\title{
Discrete element simulation of rock cutting
}

\author{
Jerzy Rojek ${ }^{\mathrm{a}, *}$, Eugenio Oñate ${ }^{\mathrm{b}}$, Carlos Labra $^{\mathrm{b}}$, Hubert Kargl $^{\mathrm{c}}$ \\ a Institute of Fundamental Technological Research, Polish Academy of Sciences, ul. Pawińskiego 5B, 02-106 Warsaw, Poland \\ ${ }^{\mathrm{b}}$ Centre Internacional de Mètodes Numèrics en Enginyeria (CIMNE), Gran Capità s/n, Edifici C1, Campus Nord UPC, 08034 Barcelona, Spain \\ c Sandvik Mining and Construction $\mathrm{GmbH}$, Zeltweg, Austria
}

\section{A R T I C L E I N F O}

Article history:

Received 14 September 2010

Received in revised form

23 March 2011

Accepted 10 June 2011

Available online 29 June 2011

Keywords:

Rock cutting

Roadheader

Discrete element method

Simulation

Numerical model

\begin{abstract}
A B S T R A C T
This paper presents numerical modelling of rock cutting processes. The model consists of a tool-rock system. The rock is modelled using the discrete element method, which is suitable to study problems of multiple material fracturing such as those involved in rock cutting. Both 2D and 3D models are considered in this work. The paper presents a brief overview of the theoretical formulation and calibration of the discrete element model by a methodology combining the dimensional analysis with simulation of the unconfined compressive strength (UCS) and indirect tension (Brazilian) tests. The rock cutting process with roadheader picks, which is typical for underground excavation, has been simulated. The results of the 2D and 3D analyses have been compared with one another, and numerical results have been compared with the available experimental data.
\end{abstract}

(c) 2011 Elsevier Ltd. All rights reserved.

\section{Introduction}

Various rock cutting works are carried out in civil as well as in mining engineering by means of different machines and cutting tools. Fig. 1 shows a typical design of a conical point attack pick, a cutting tool used at roadheaders, machines performing rock cutting in underground excavations. The basic physical phenomenon occurring during rock cutting is fracturing and fragmentation of the rock under mechanical action of a cutting tool. Rock failure mechanism during cutting depends on many factors, most important being the type of rock and rock properties, tool geometry and its position with respect to the rock. Depending on the type of rock we can distinguish brittle and ductile failure. Rock chips are formed and separated due to combined action of shear and tensile fracture initiated in a crushing zone near the tooth tip and propagating into the intact rock.

Optimization of cutting tool design and determination of optimum process parameters require knowledge about the cutting process, which can be gained by practical investigation and measurements as well as by realistic simulation activities. The cutting process itself is influenced by three different groups of factors: (i) properties of rock and rock mass, (ii) design of the cutting tool, its orientation with respect to its trajectory, physical properties of the cutting tools and supporting and driving unit

\footnotetext{
* Corresponding author.

E-mail addresses: jrojek@ippt.gov.pl (J. Rojek), onate@cimne.upc.edu (E. Oñate), clabra@cimne.upc.edu (C. Labra), Hubert.Kargl@sandvik.com (H. Kargl).
}

such as mass, stiffness and damping, (iii) operational parameters such as cutting depth, cutting speed, line spacing and type of cooling. All these factors influence the performance and efficiency of the cutting process, which can be evaluated by comparison of cutting forces inclusive their variation, cutting rate and specific energy and finally the tool wear and its life time $[2,5,7,13]$.

Different models have been used to predict cutting force for given cutting tool and rock properties. These models are based on experimental, analytical and numerical approaches. Experimental investigations of rock cutting allow us to identify parameters influencing cutting forces and obtain relationships between cutting forces and these parameters [20,31]. Cutting tests performed under different conditions: different kinds of rock, different pick geometry and different kinematic parameters produced a formula for mean cutting force as a function of the rock compressive strength, cutting depth and tip diameter [20].

Experimental studies of rock cutting enabled better understanding of rock-tool interaction and provided information necessary for theoretical modelling. Simple analytical models have been created in attempt to describe the cutting processes, particularly those with brittle failure. One of the earliest models is a 2D model developed by Evans [7] for rock cutting with drag picks. In this model it is assumed that the breakage mechanism is essentially tensile and occurs along the failure surface, which approximates a circular arc. Evans' theory was used by other researchers to explain the general failure mechanism of rocks $[30,25]$. Another two-dimensional model has been developed by Nishimatsu who assumed that failure is purely due to shear and occurs along a plane [22]. Principles of fracture mechanics were 


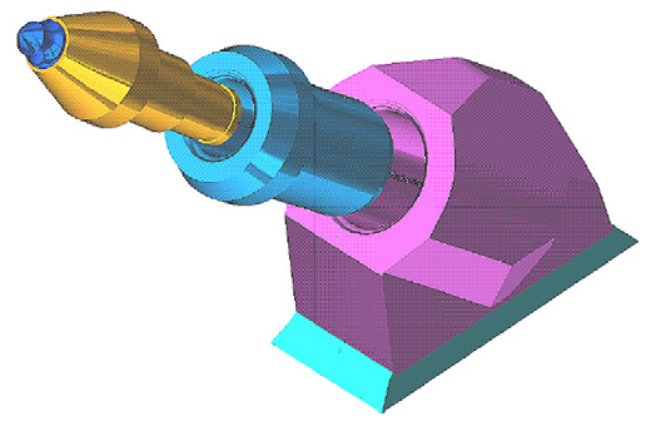

Fig. 1. Typical design of a point attack pick.

used to study theoretically crack propagation paths and corresponding load requirement during rock cutting by Guo et al. [10].

Analytical models, like those developed by Evans [7] or Nishimatsu [22], are based on simplified assumptions. The complex stress state and crack propagation patterns involved in the process of rock cutting made it difficult for theoretical analysis. The rock failure process during cutting can be traced in more detail by appropriate numerical methods.

A number of numerical studies of rock cutting utilized the finite element method, cf. $[14,15,12,33,26]$. However, the finite element method based on the continuum mechanics theory of material modelling has serious problems in representing properly discontinuities of the material occurring during rock cutting [12]. Special formulations are necessary to introduce the possibility of discontinuum analysis of rock fracture. One of the simplest solutions consists in removal of damaged finite elernents on reaching a certain failure criterion. This method is implemented in the LS-Dyna software and it was applied to simulate rock
fragmentation in the rotary rock cutting [33]. Geometrical fea of rock cutting advance were represented adequately, bu no quantitative results of cutting forces were given in this work. Fracture mechanics approach incorporated in the finite element

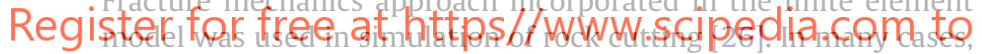
however, analysis of rock cutting by the finite element method is limited to the initial stage of major chip formation since the formulation used does not allow for the continuation of the analysis in the post-failure stage $[12,26]$.

The discrete element method can take into account most kinds of discontinuities and material failure characterized with multiple fracture which makes it a suitable tool to study rock cutting $[11,29,27]$. The discrete element code PFC2D was successfully applied to simulation of rock cutting by Huang [11]. The same model was used in [19] to study rock cutting under hydrostatic pressure. Drilling tests have been simulated using a two-dimensional discrete element model and the results were compared with the continuum-based finite element analysis in [27]. A 3D discrete element model of rock cutting with conical picks was developed by Su et al. [29] and by Su and Akcin [28]. Rock chipping process performed by two neighboring TBM disc cutters was simulated by 2D DEM code UDEC [9]. The influence of different cutter spacings on TBM fragmentation efficiency has been studied. The UDEC software was also used to model rock destruction during cutting in [21]. Hybrid DEM-FEM model of rock cutting was presented in [23].

Most of the above cited works employ 2D models. There are very few numerical studies which consider 3D geometry $[33,29,28]$. Some of the 3D models of rock cutting have not given accurate quantitative results [28]. The current work presents both 2D and 3D discrete element modelling and simulations of rock cutting. Comparisons between $2 \mathrm{D}$ and $3 \mathrm{D}$ results are made showing a range of validity of the $2 \mathrm{D}$ modelling and its limitation.
Numerical results are also validated using experimental results obtained in laboratory tests of the rock cutting.

\section{Numerical model of rock cutting}

A system consisting of a tool and rock sample is considered in the model (Fig. 2). The rock material is represented as a collection of spherical (in 3D) or cylindrical (in 2D) discrete elements interacting among themselves with contact forces. The tool is considered as a rigid body. Its surface is discretised with triangular facets. The tool-rock interaction is modelled assuming the Coulomb friction model. A numerical model of rock cutting has been developed within the authors' own implementation of the discrete element method (DEM) in the DEMPack computer program $[23,24]$.

\section{Discrete element method formulation}

\subsection{Equations of motion}

The translational and rotational motion of the rigid spherical or cylindrical elements (particles) is governed by the standard equations of rigid body dynamics. For the $i$-th element (Fig. 3) we have

$m_{i} \ddot{\boldsymbol{u}}_{i}=\boldsymbol{F}_{i}$,

(1)

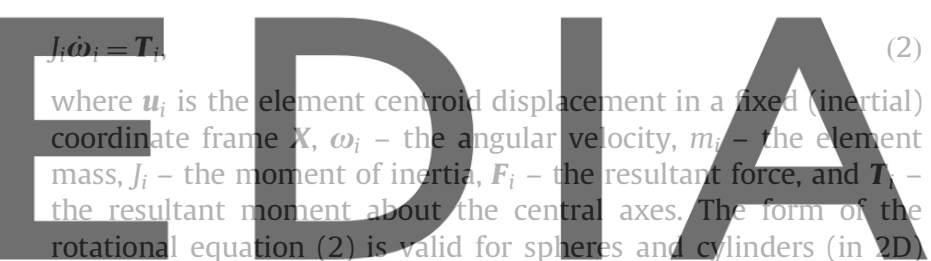

and is simplified with respect to a general form for an arbitrary rigid body with the rotational inertial properties represented by a

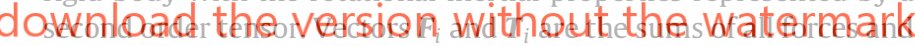
moments applied to the $i$-th element due to external load, $\boldsymbol{F}_{i}^{\text {ext }}$ and $\boldsymbol{T}_{i}^{\text {ext }}$, respectively, the contact interactions with neighbouring

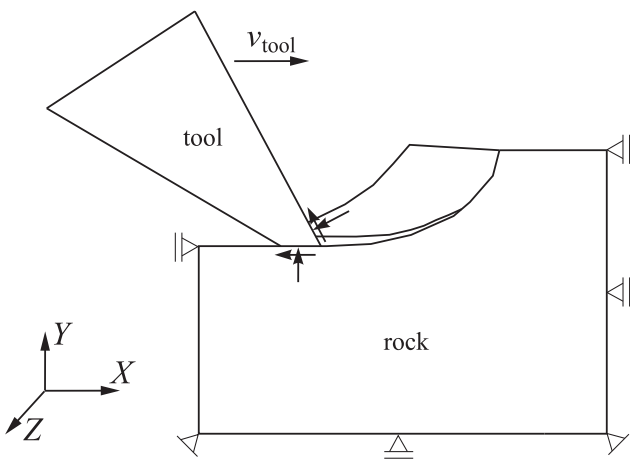

Fig. 2. Geometrical scheme of a rock cutting model.

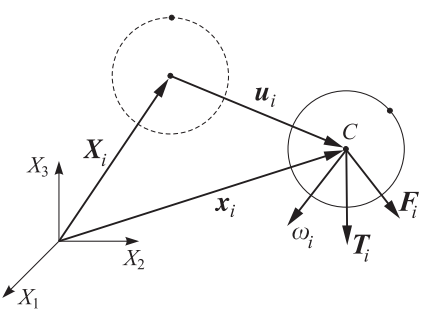

Fig. 3. Motion of a discrete element. 


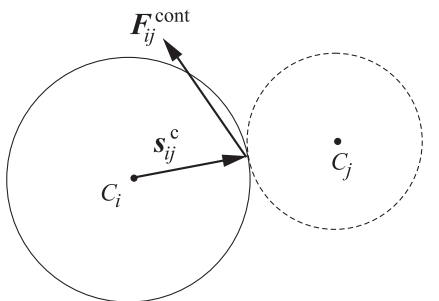

Fig. 4. Contact interaction between two discrete elements.

spheres, $\boldsymbol{F}_{i j}^{\text {cont }}, j=1, \ldots, n_{i}^{\mathrm{c}}$, where $n_{i}^{\mathrm{c}}$ are the number of elements being in contact with the $i$-th discrete element, and the forces and moments resulting from external damping, $\boldsymbol{F}_{i}^{\text {damp }}$ and $\boldsymbol{T}_{i}^{\text {damp }}$, respectively:

$\boldsymbol{F}_{i}=\boldsymbol{F}_{i}^{\mathrm{ext}}+\sum_{j=1}^{n_{i}^{\mathrm{c}}} \boldsymbol{F}_{i j}^{\mathrm{cont}}+\boldsymbol{F}_{i}^{\mathrm{damp}}$,

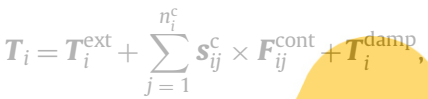

where $\boldsymbol{s}_{i j}^{\mathrm{c}}$ is the vector connecting the centre of mass of the $i$-th element with the contact point with the $j$-th element (Fig. 4).

\subsection{Constitutive model}

Contact forces $\boldsymbol{F}_{i j}^{\text {cont }}$ are evaluated using a constitutive model formulayed for the interaction between particles. Modes of
contact interaction employ the decomposition of the contact
force between two elements $\boldsymbol{F}^{\text {cont }}$ into normal and tangential
components, $\boldsymbol{F}_{\mathrm{n}}^{\mathrm{cont}}$ and $\boldsymbol{F}_{\mathrm{t}}^{\mathrm{cont}}$, respectively
$\boldsymbol{F}^{\mathrm{cont}}=\boldsymbol{F}^{\mathrm{cont}}+\boldsymbol{F}_{\mathrm{t}}^{\text {cont }}$
The decomposition of the contact force vector can also be presented in the form

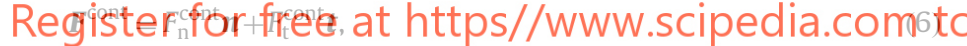

where $\boldsymbol{n}$ and $\boldsymbol{t}$ are orthogonal unit base vectors, $\boldsymbol{n}$ is normal to the particle surface at the contact point, and $t$ is the unit tangent vector collinear with the tangent force, $F_{\mathrm{n}}^{\text {cont }}$ and $F_{\mathrm{t}}^{\text {cont }}$ are scalar quantities obtained by projection of the vector $\boldsymbol{F}^{\text {cont }}$ on the base vectors $\boldsymbol{n}$ and $\boldsymbol{t}$.

In the present work, the rock materials are modelled using the elastic perfectly brittle model of contact interaction. This model assumes cohesive bonding between neighbouring particles. These bonds can be broken under excessive loading, which allows us to simulate initiation and propagation of material fracture. The force-displacement relationships for the normal and tangential contact interaction in the elastic perfectly brittle model are shown in Fig. 5.

When two particles are bonded the contact forces in both normal and tangential directions are calculated from the linear constitutive relationships:

$F_{\mathrm{n}}^{\text {cont }}=k_{\mathrm{n}} u_{\mathrm{n}}$,

$\left\|\boldsymbol{F}_{\mathrm{t}}^{\text {cont }}\right\|=k_{\mathrm{t}}\left\|\boldsymbol{u}_{\mathrm{t}}\right\|$,

where $F_{\mathrm{n}}^{\text {cont }}$ - normal contact force, $\boldsymbol{F}_{\mathrm{t}}^{\text {cont }}$ - tangential contact force, $k_{\mathrm{n}}$ - interface stiffness in the normal direction, $k_{\mathrm{t}}$ - interface stiffness in the tangential direction, $u_{\mathrm{n}}$ - normal relative displacement, $\boldsymbol{u}_{\mathrm{t}}-$ tangential relative displacement. It is possible to specify different values for normal stiffness $k_{\mathrm{n}}$ in the tension and compression. However, in the present work in order to minimize the number of parameters to calibrate the same stiffness for tension and compression is assumed.
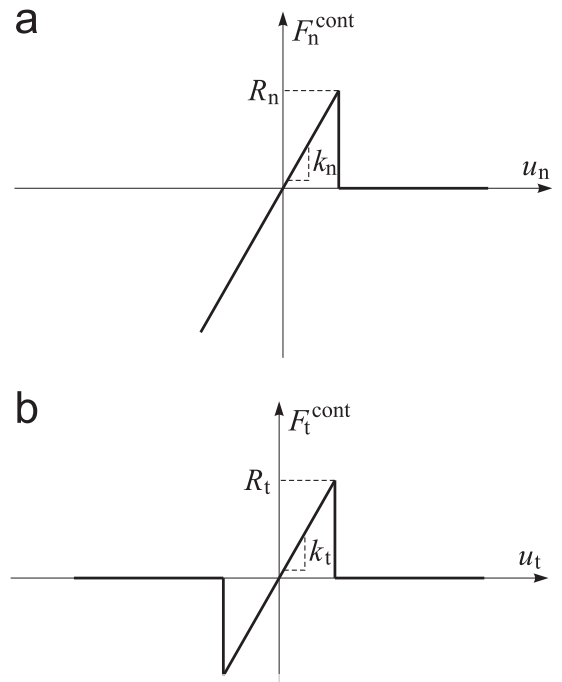

Fig. 5. Force-displacement relationships for the elastic perfectly brittle model (a) in the normal direction, (b) in the tangential direction.

Cohesive bonds are broken instantaneously when the interface strength is exceeded in the tangential direction by the tangential contact force or in the normal direction by the tensile contact force. The failure (decohesion) criterion can be written as
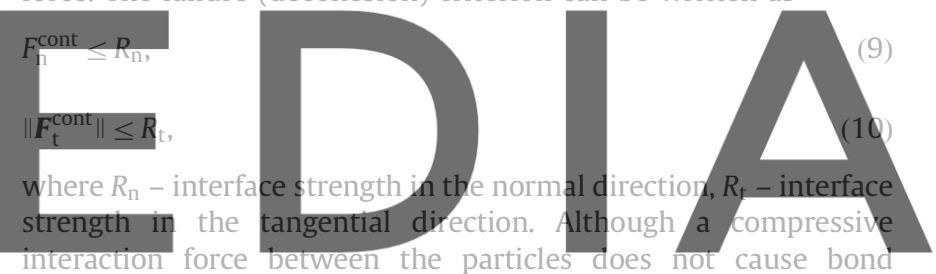

breakage, material damage under macroscopic compression can

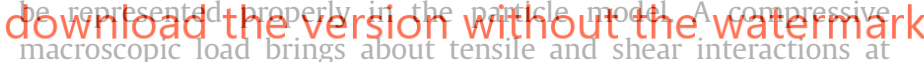

the microscopic level which may lead to bond failures.

After breakage of cohesive bonds a frictional interaction can occur among particles. Friction force is evaluated assuming the Coulomb model of friction:

$\left\|\boldsymbol{F}_{\mathrm{t}}^{\mathrm{cont}}\right\|=\mu\left|F_{\mathrm{n}}^{\text {cont }}\right|$,

where $\mu$ is the Coulomb friction coefficient.

A quasi-static state of equilibrium of the assembly of particles can be achieved by application of adequate damping. Damping is necessary to dissipate kinetic energy. Damping terms $\boldsymbol{F}_{i}^{\text {damp }}$ and $\boldsymbol{T}_{i}^{\text {damp }}$ in the Eqs. (3) and (4) in this work are of non-viscous type and are given by

$\boldsymbol{F}_{i}^{\text {damp }}=-\alpha^{t}\left\|\boldsymbol{F}_{i}^{\text {ext }}+\boldsymbol{F}_{i}^{\text {cont }}\right\| \frac{\dot{\boldsymbol{u}}_{i}}{\left\|\dot{\boldsymbol{u}}_{i}\right\|}$,

$\boldsymbol{T}_{i}^{\text {damp }}=-\alpha^{r}\left\|\mathbf{T}_{i}\right\| \frac{\omega_{i}}{\left\|\omega_{i}\right\|}$.

where $\alpha^{t}$ and $\alpha^{r}$, are, respective, damping constants for translational and rotational motion.

\subsection{Time integration of equations of motion}

Equations of motion (1) and (2) are integrated in time using an explicit central difference type algorithm, the so-called leap-frog method. Time integration of Eq. (1) within this algorithm is based on the following finite difference schemes for accelerations and 
velocities:

$\ddot{\boldsymbol{u}}_{i}^{n}=\frac{\dot{\boldsymbol{u}}_{i}^{n+1 / 2}-\dot{\boldsymbol{u}}_{i}^{n-1 / 2}}{\Delta t}$,

$\dot{\boldsymbol{u}}_{i}^{n+1 / 2}=\frac{\boldsymbol{u}_{i}^{n+1}-\boldsymbol{u}_{i}^{n}}{\Delta t}$,

where accelerations, $\ddot{\boldsymbol{u}}_{i}^{n}$, and positions, $\boldsymbol{u}_{i}^{n}$ and $\boldsymbol{u}_{i}^{n+1}$, are defined at time instants $t^{n}$ and $t^{n+1}\left(t^{n+1}=t^{n}+\Delta t\right)$, while velocities, $\dot{\boldsymbol{u}}_{i}^{n-1 / 2}$ and $\dot{\boldsymbol{u}}_{i}^{n+1 / 2}$, are shifted by a half-step. Employing the formulae (14) and (15) for Eq. (1) the following time integration algorithm for the translational motion is obtained:

$\ddot{\boldsymbol{u}}_{i}^{n}=\frac{\boldsymbol{F}_{i}^{n}}{m_{i}}$,

$\dot{\boldsymbol{u}}_{i}^{n+1 / 2}=\dot{\boldsymbol{u}}_{i}^{n-1 / 2}+\ddot{\boldsymbol{u}}_{i}^{n} \Delta t$,

$\boldsymbol{u}_{i}^{n+1}=\boldsymbol{u}_{i}^{n}+\dot{\boldsymbol{u}}_{i}^{n+1 / 2} \Delta t$.

Introducing a finite difference expression for rotational accelerations by analogy to the formula (14) in the form

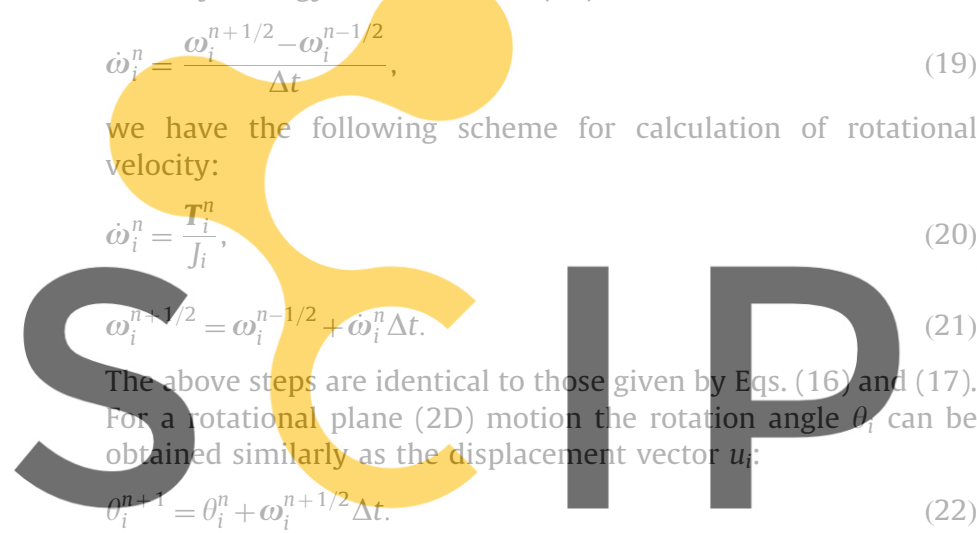

In a three-dimensional motion, however, the rotational position

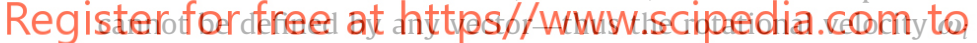
cannot be integrated, cf. [1]. In our case, because we deal with spherical particles and tangential forces are calculated incrementally, it is sufficient to calculate the vector of incremental rotation $\Delta \boldsymbol{\theta}_{i}$. Using the formula analogical to (15) we have

$\Delta \boldsymbol{\theta}_{i}=\omega_{i}^{n+1 / 2} \Delta t$

An explicit integration in time yields high computational efficiency of the solution for a single step. The disadvantage of the explicit integration scheme is its conditional numerical stability imposing the limitation on the time step $\Delta t$. The time step $\Delta t$ must not be larger than the critical time step $\Delta t_{\mathrm{cr}}$ :

$\Delta t \leq \Delta t_{\mathrm{cr}}$

determined by the highest natural frequency of the system $v_{\max }$,

$\Delta t_{\mathrm{cr}}=\frac{2}{v_{\max }}$.

An exact determination of the highest frequency $v_{\max }$ would require a solution of the eigenvalue problem defined for the whole system of connected rigid particles. The maximum frequency of the whole system can be estimated as the maximum of natural frequencies $v_{i}^{e}$ of subsets of the connected particles surrounding each particle $e, \mathrm{cf}$. [4]:

$v_{\max } \leq v_{\max }^{D}, \quad$ where $v_{\max }^{D}=\max _{i, e} v_{i}^{e}$

In the implemented algorithm a further simplification is assumed. The maximum frequency is estimated as the maximum of natural frequencies of the mass-spring systems defined for all the particles characterized by the particle mass, $m_{e}$, and the spring stiffness assumed to be equal to the contact interface stiffness in the normal direction $k_{n}$. The natural frequency of such a system is given by the following equation:

$v^{e}=\sqrt{\frac{k_{n}}{m_{e}}}$

This frequency is used to calculate the critical time step for each mass-spring system

$\Delta t^{e}=\frac{2}{v^{e}}$.

The stable time step for all the discrete element assembly is estimated taking the minimum value of the time steps calculated from Eq. (28)

$\Delta t_{\min }^{e}=\min _{e} \Delta t^{e}$

and a certain safety factor $\alpha$

$\Delta t=\alpha \Delta t_{\min }^{e}$

Numerical tests show that the formula (30) with $\alpha=0.1-0.2$ gives a good estimation of the stable time step for the discrete element model.

\section{Determination of rock model parameters}

The discrete element model can be regarded as a micromecha-

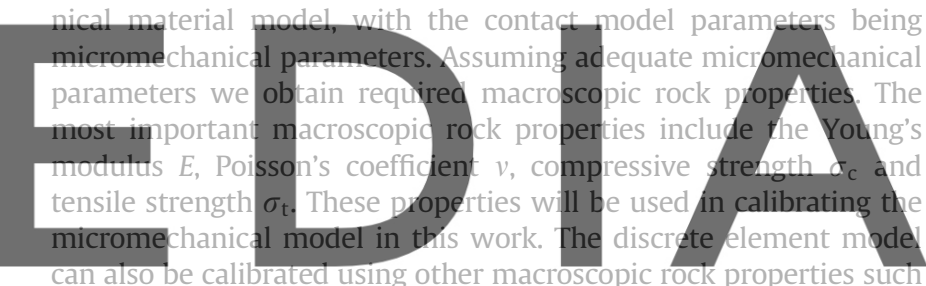

as the shear strength, the angle of internal friction or the fracture dowplogd the version without the watermark me set of constitutive micromechanical parameters defining the elastic-brittle model of interaction between discrete elements, that is described in Section 3, consists of the following parametric quantities:

$k_{\mathrm{n}} \quad$ contact stiffness in the normal direction,

$k_{\mathrm{t}} \quad$ contact stiffness in the tangential direction,

$R_{\mathrm{n}} \quad$ interface strength in the normal direction,

$R_{\mathrm{t}} \quad$ interface strength in the tangential direction,

$\mu \quad$ Coulomb friction coefficient,

$\alpha^{t} \quad$ damping coefficient for translational motion,

$\alpha^{r} \quad$ damping coefficient for rotational motion.

Determination of the model parameters is the key issue in the use of the discrete element method.

\subsection{Dimensionless micro-macro relationships}

In the present work the micromechanical parameters have been determined using the methodology developed by Huang [11], based on the combination of the dimensional analysis with numerical simulation of the standard laboratory tests for rocks, the unconfined compression test and the Brazilian test. This methodology was later used in other works, cf. [8,32].

Dimensional analysis is based on the Buckingham $\pi$ theorem, which states that any physically meaningful functional relationship of $N$ variables $\Psi\left(Q_{1}, Q_{2}, \ldots, Q_{N}\right)$ can be expressed equivalently by a function of $N-p$ dimensionless parameters $\Phi\left(\pi_{1}, \pi_{2}, \ldots, \pi_{N-p}\right)$, where $p$ is the number of primary dimensions (minimum 
independent dimensions required to specify the dimensions of all the relevant parameters), and $N-p$ is the maximum number of independent parameters [18].

Here, we will search functions defining the macroscopic material parameters: Young's modulus E, Poisson's ratio $v$, compressive strength $\sigma_{\mathrm{c}}$ and tensile strength $\sigma_{\mathrm{t}}$ in terms of microscopic parameters: $k_{\mathrm{n}}, k_{\mathrm{t}}, R_{\mathrm{n}}, R_{\mathrm{t}}, \mu, \alpha^{\mathrm{t}}, \alpha^{r}$. Macroscopic properties also depend on other parameters related with the particle assembly characterization, such as the average particle radius $r$, material density $\rho$ and porosity of the particle assembly $n$. All these parameters are strongly related with the assembly generation algorithm. The set of the parameters can be completed with geometrical parameters represented by the specimen size $L$ (due to possible scale effect) and loading velocity $V$. Thus, the number of relevant parameters $N$ is 12 . We have three primary dimensions involved: mass, length, time $(p=3)$. We can assume that there are nine independent parameters.

The set of parameters is not unique and can be modified by taking into account some other parameters that can influence macroscopic properties. In [32] the minimum and maximum element radii, $r_{\min }$ and $r_{\max }$, respectively, have been included to the relevant parameters in order to better consider the influence of the element size distribution on macroscopic properties. This influence is taken into account indirectly in our formulation through the use of the porosity $n$ which depends on the size distribution. The wider size distribution the lower porosity in the discrete element model can be achieved.

Having in mind there are alternative approaches, our procedure is based on the following set of nine independent para-
meters? $\left\{k_{\mathrm{n}} r / R_{\mathrm{n}}, R_{\mathrm{t}} / R_{\mathrm{n}}, k_{\mathrm{t}} / k_{\mathrm{n}}, n, r / L, \mu, \alpha, \alpha^{\mathrm{r}}, V / \sqrt{\left.k_{\mathrm{n}} / \rho\right\} \text {. Since the }}\right.$
material properties will be studied under quasi-static conditions,
the set of parameters can be reduced by removing $V / \sqrt{k_{\mathrm{n}} / \rho, \alpha^{\mathrm{t}}}$
and $\alpha$. Further on, assuming that the element size $r$ is small
compared to macroscopic dimension $L(r<L)$, we can neglect the
influence of the parameter $r / L$. The friction coefficient $\mu$ has

influence mainly on the post-failure material behaviour, so we can omit it in the relationships for elastic constants and strength

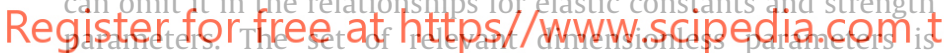

reduced to the following list: $\left\{k_{\mathrm{n}} r / R_{\mathrm{n}}, R_{\mathrm{t}} / R_{\mathrm{n}}, k_{\mathrm{t}} / k_{\mathrm{n}}, n\right\}$. Assuming that the elastic constants are determined in the range, in which the failure is not initiated yet, in the relationships for elastic constants we can consider only two dimensionless parameters: $\left\{k_{\mathrm{t}} / k_{\mathrm{n}}, n\right\}$. Thus, the following dimensionless functional relationships linking macroscopic and microscopic parameters can be postulated for a discrete element model, cf. [11]:

$$
\begin{aligned}
& \frac{E l}{k_{n}}=\Phi_{E}\left(\frac{k_{\mathrm{t}}}{k_{n}}, n\right), \\
& v=\Phi_{v}\left(\frac{k_{\mathrm{t}}}{k_{n}}, n\right), \\
& \frac{\sigma_{\mathrm{c}} A}{R_{n}}=\Phi_{c}\left(\frac{R_{\mathrm{t}}}{R_{n}}, \frac{k_{\mathrm{t}}}{k_{n}}, n\right), \\
& \frac{\sigma_{\mathrm{t}} A}{R_{n}}=\Phi_{t}\left(\frac{R_{\mathrm{t}}}{R_{n}}, \frac{k_{\mathrm{t}}}{k_{n}}, n\right),
\end{aligned}
$$

where $l$ is a certain length parameter and $A$ is a characteristic area related to the discrete element model. The characteristic length $l$ and area $A$ will be defined in a different way in 2D and 3D problems. In the case of the 2D problem, where cylindrical particles are used, it is convenient to take $l$ as equal to the length (height) of the particles, with a unitary value. In the 3D problem, the characteristic length can be defined by the average radius $r$ of the particles, in equivalence with the 2D problem, but considering spherical particles. The characteristic area $A$ for 2D problem is

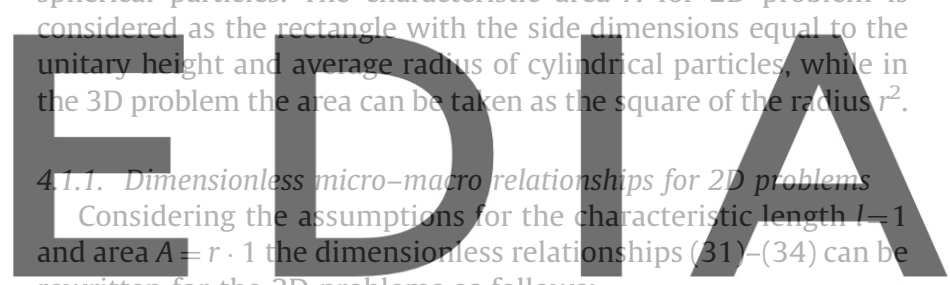
rewritten for the 2D problems as follows:

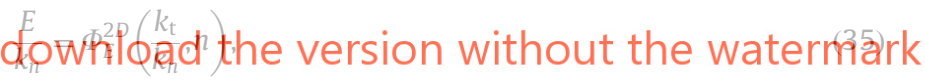
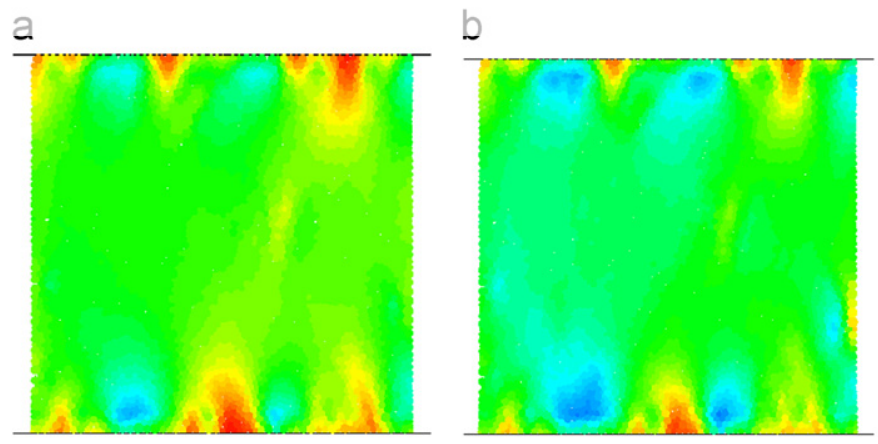

C

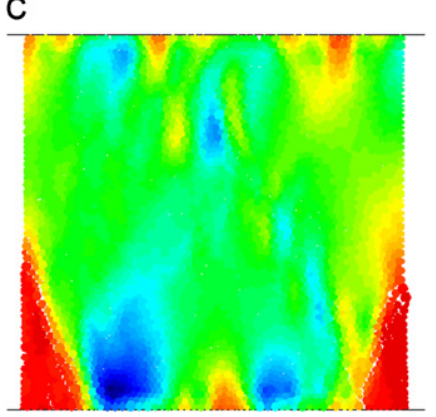

d

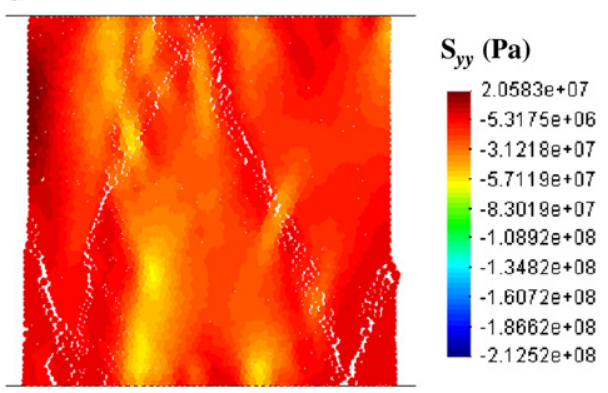

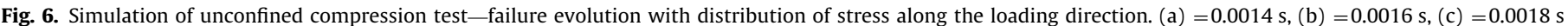
and $(\mathrm{d})=0.0020 \mathrm{~s}$. 
$v=\Phi_{v}^{2 D}\left(\frac{k_{\mathrm{t}}}{k_{n}}, n\right)$

$\frac{\sigma_{\mathrm{c}} r}{R_{n}}=\Phi_{c}^{2 D}\left(\frac{R_{\mathrm{t}}}{R_{n}}, \frac{k_{\mathrm{t}}}{k_{n}}, n\right)$

$\frac{\sigma_{\mathrm{t}} r}{R_{n}}=\Phi_{t}^{2 D}\left(\frac{R_{\mathrm{t}}}{R_{n}}, \frac{k_{\mathrm{t}}}{k_{n}}, n\right)$

The specific form of the dimensionless relationships (35)-(38) have been obtained from the results of numerical simulations of the unconfined compression test (UCS) and Brazilian tests. The results of a simulation of the UCS test are presented in Fig. 6 in the form of failure evolution with distribution of stresses in the direction of loading. The material sample of $50 \times 50 \mathrm{~mm}$ represented by an assembly of randomly compacted 4979 discs with a radii range $0.262-0.653 \mathrm{~mm}$ (average radius $0.465 \mathrm{~mm}$ ) has been generated using the high density sphere packing algorithm developed in [17]. Compaction of the particle assembly has been characterized by a

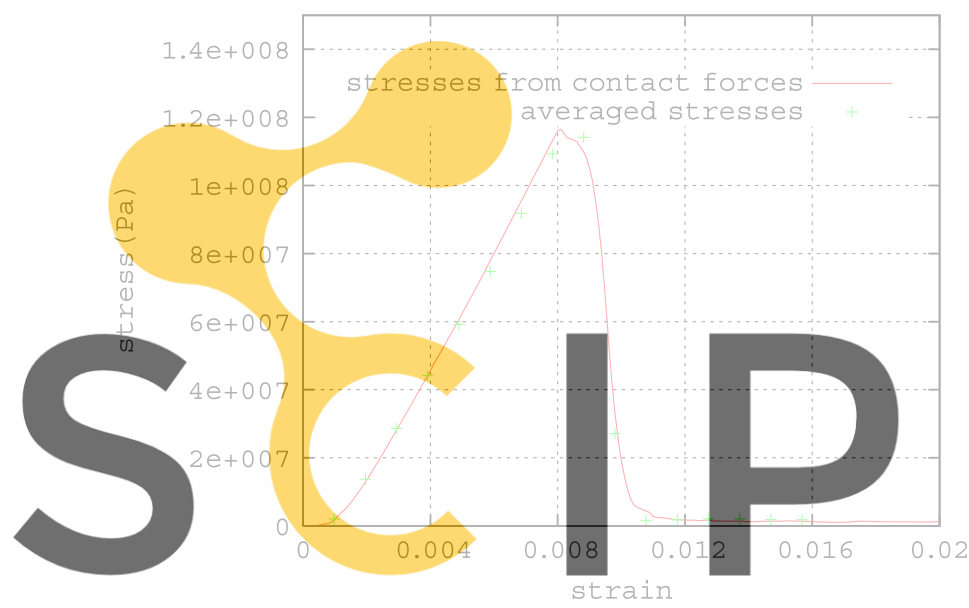

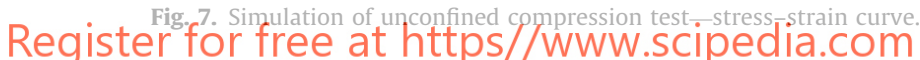

a

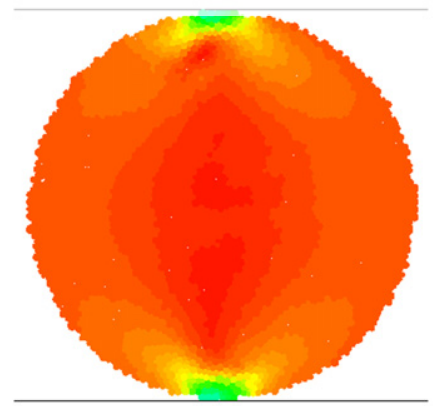

C

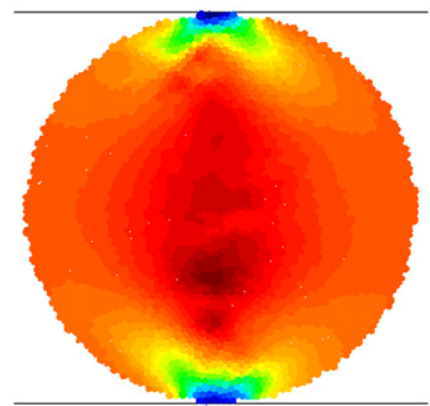

porosity $n$ of $13 \%$. The stress-strain curve obtained in the analysis (Fig. 7) can be used to determine the Young's modulus $E$ and compressive strength $\sigma_{\mathrm{c}}$. The simulation also provides the value of the Poisson's ratio $v$. The dimensionless relationships (35)-(38) are valid for discrete element models characterized with a similar porosity as that of the specimen used in the calibration procedure. The effect of the porosity has not been studied for other micromacro relationships in this work either.

The cylindrical specimen of the diameter $50 \mathrm{~mm}$ for the simulation of the Brazilian test has been obtained by trimming adequately the specimen used in the UCS modelling. The failure mode with distributions of averaged stresses in the direction normal to the loading is shown in Fig. 8. The failure in the form of splitting along the diameter parallel to the loading predicted in simulation corresponds very well to the experimental observations. The stress distribution is in a very good agreement with the theoretical solution [34].

The force-time curve obtained in the simulation is plotted in Fig. 9. Taking the maximum force $P_{\max }$ we find the tensile strength as

$$
\sigma_{t}=\frac{2 P_{\max }}{\pi L D}
$$

Simulations of both the UCS and Brazilian test have been performed for the dimensionless parameter $k_{t} / k_{n}$ in the range from 0 to 1.5 , assuming $k_{n}=1.6 \times 10^{10} \mathrm{~N} / \mathrm{m}, R_{n}=3 \times 10^{4} \mathrm{~N}$, $R_{t} / R_{n}=1$. Results of the analyses are summarized in Table 1 . The curves representing the dimensionless relationships (35)-(38), based on the results from Table 1, are plotted in Figs. 10 and 11. Our

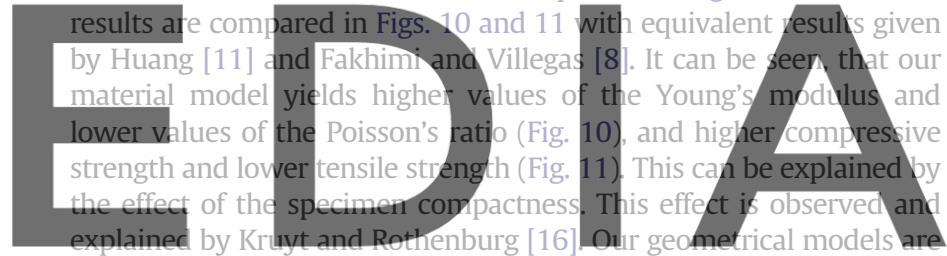
generated with a special algorithm ensuring high compactness of

\section{to download the version without the watermark}

b

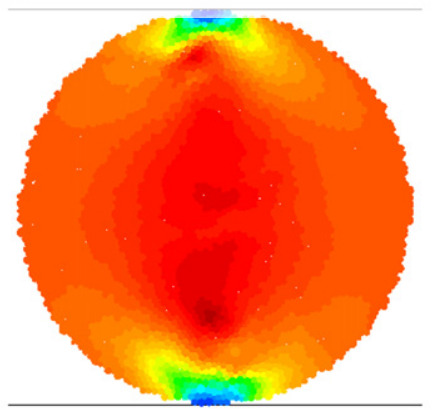

d

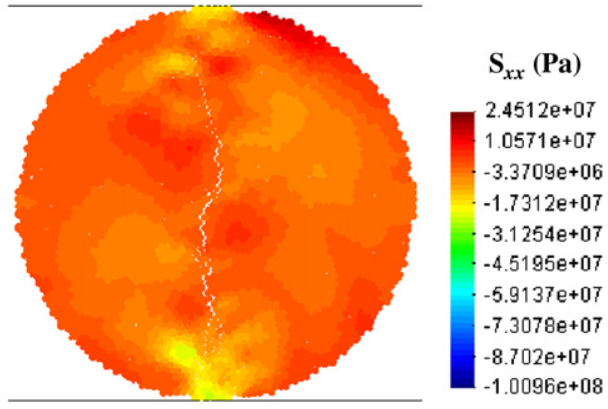

Fig. 8. Simulation of Brazilian test-failure of the rock sample with distribution of stress in the direction normal to the loading. (a) $=0.0010 \mathrm{~s}$, (b) $=0.0014 \mathrm{~s}$, (c) $=0.0016 \mathrm{~s}$ and $(\mathrm{d})=0.0018 \mathrm{~s}$. 


\subsubsection{Dimensionless micro-macro relationships for 3D problems}

Considering the assumptions for the characteristic length $l=r$ and area $A=r^{2}$ the dimensionless relationships (31)-(34) can be

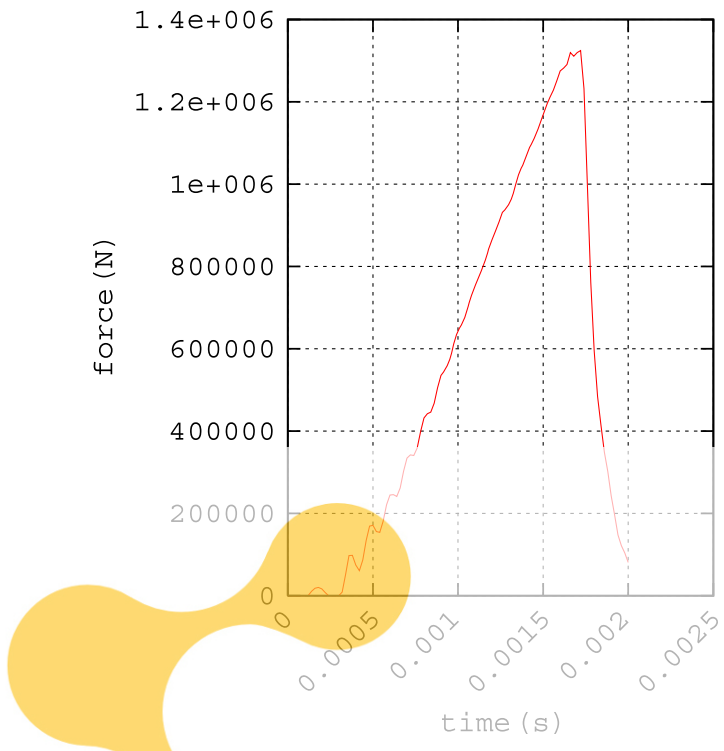

Fig. 9. Simulation of the Brazilian test-load-time curve.

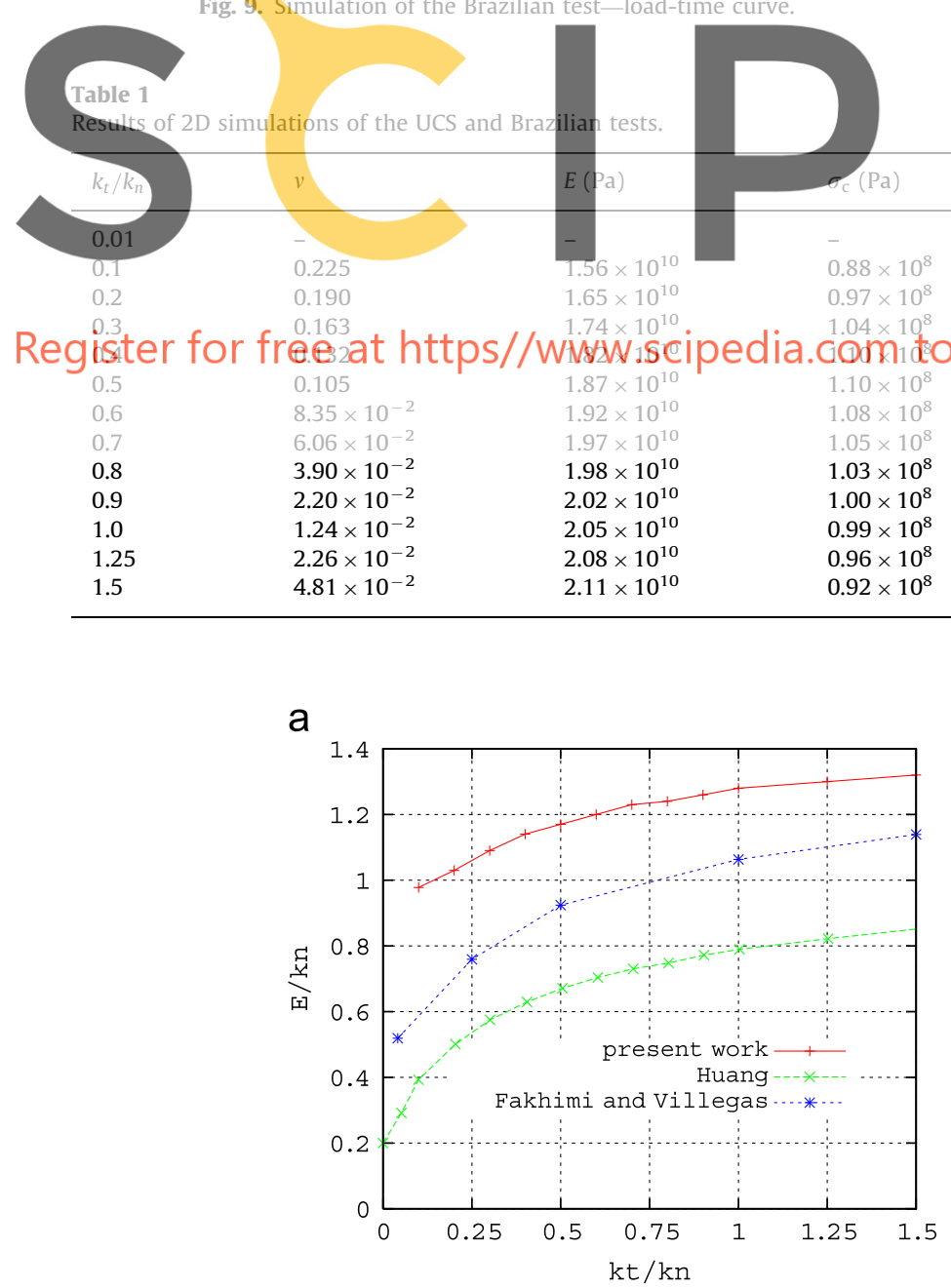

rewritten for the $3 \mathrm{D}$ problems as follows:

$\frac{E r}{k_{n}}=\Phi_{E}^{3 D}\left(\frac{k_{\mathrm{t}}}{k_{n}}, n\right)$,

$v=\Phi_{v}^{3 D}\left(\frac{k_{\mathrm{t}}}{k_{n}}, n\right)$,

$\frac{\sigma_{\mathrm{c}} r^{2}}{R_{n}}=\Phi_{c}^{3 D}\left(\frac{R_{\mathrm{t}}}{R_{n}}, \frac{k_{\mathrm{t}}}{k_{n}}, n\right)$,

$\frac{\sigma_{\mathrm{t}} r^{2}}{R_{n}}=\Phi_{t}^{3 D}\left(\frac{R_{\mathrm{t}}}{R_{n}}, \frac{k_{\mathrm{t}}}{k_{n}}, n\right)$.

The specific form of the dimensionless relationships have been obtained from the results of numerical simulations of the laboratory tests. Results of the numerical simulation of the UCS and Brazilian tests are shown in Fig. 12. The failure obtained in simulation is similar to the failure observed in the experiments.

A cylindrical specimen for the UCS simulation, whose diameter and height both are equal to $50 \mathrm{~mm}$, has been discretized with 11,120 particles with average radius of $1.12 \mathrm{~mm}$. A half of this specimen, with diameter of $50 \mathrm{~mm}$ and height of $25 \mathrm{~mm}$, obtained by removing the other half from the UCS, was used for simulation of the Brazilian test. The simulations have been performed for the dimensionless parameter $k_{t} / k_{n}$ in the range from 0 to 1 , assuming $k_{n}=5 \times 10^{7} \mathrm{~N} / \mathrm{m}, R_{n}=2 \times 10^{2} \mathrm{~N}$, and $R_{t} / R_{n}=1$. The results of the analyses are summarized in Table 2. The dimensionless relationships (40)-(42) obtained from

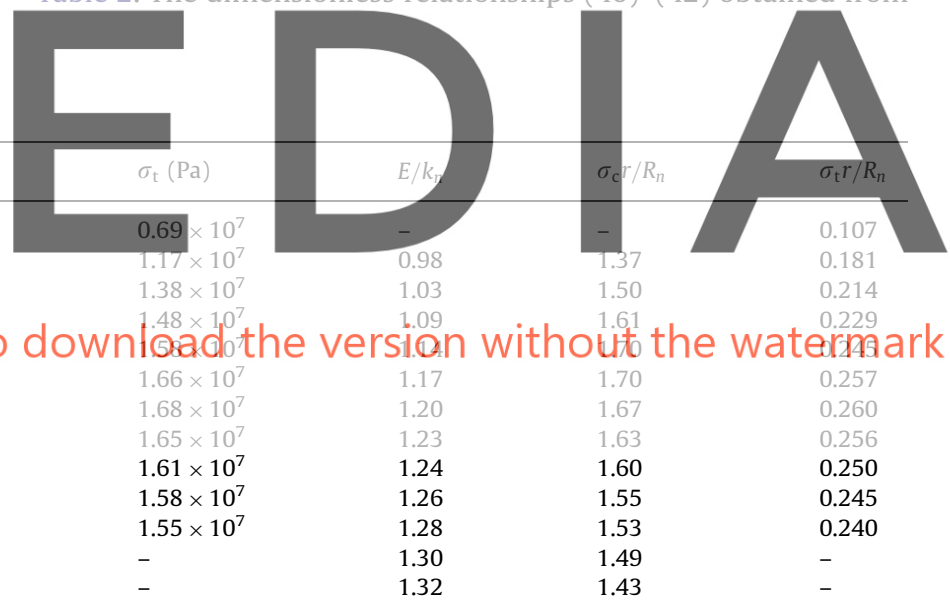

b

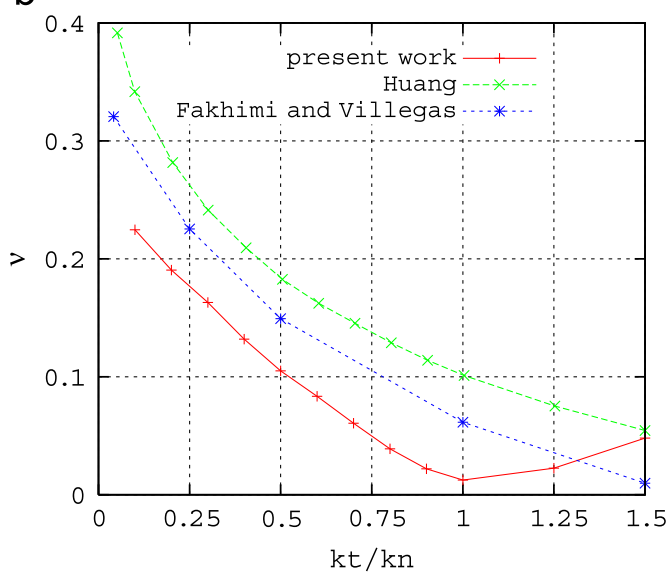

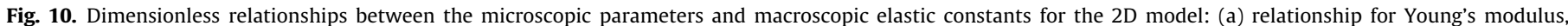
(b) relationship for Poisson's ratio. 
a

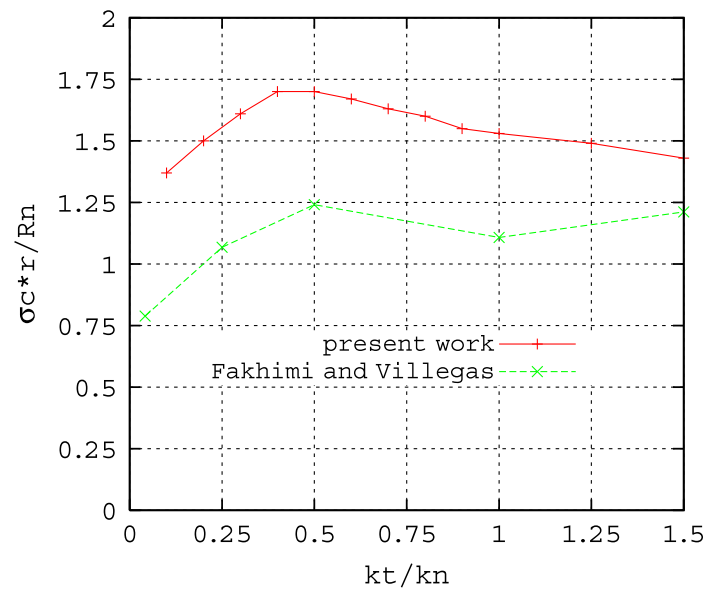

b

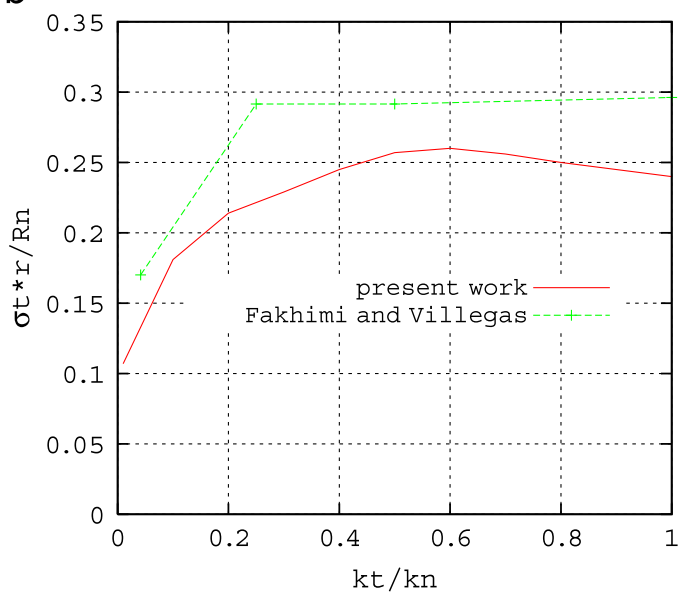

Fig. 11. Dimensionless relationships between the microscopic parameters and (a) compressive strength, (b) tensile strength for the $2 \mathrm{D}$ model

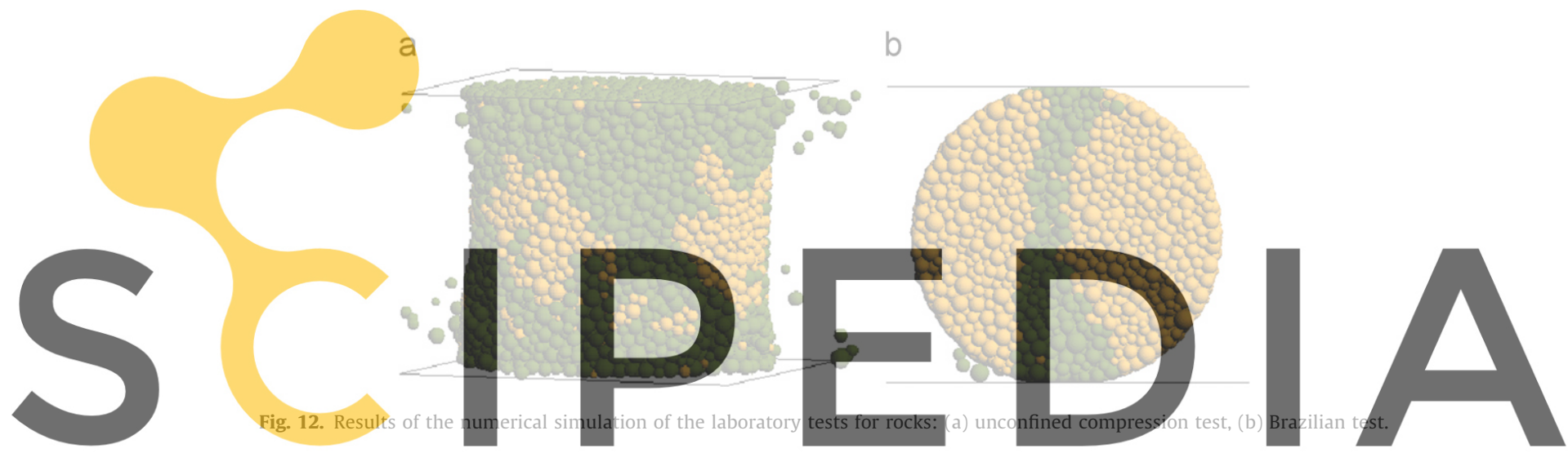

Table 2

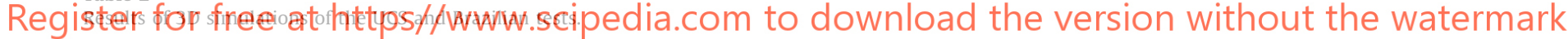

\begin{tabular}{|c|c|c|c|c|c|c|c|}
\hline$k_{t} / k_{n}$ & $v$ & $E(\mathrm{~Pa})$ & $\sigma_{\mathrm{c}}(\mathrm{Pa})$ & $\sigma_{\mathrm{t}}(\mathrm{Pa})$ & $\mathrm{Er} / k_{n}$ & $\sigma_{\mathrm{c}} r^{2} / R_{n}$ & $\sigma_{t} r^{2} / R_{n}$ \\
\hline 0.01 & 0.328 & $1.99 \times 10^{10}$ & $0.655 \times 10^{8}$ & $1.00 \times 10^{7}$ & 0.4457 & 0.4106 & 0.0628 \\
\hline 0.1 & 0.258 & $2.41 \times 10^{10}$ & $1.36 \times 10^{8}$ & $1.77 \times 10^{7}$ & 0.5408 & 0.8535 & 0.1113 \\
\hline 0.2 & 0.217 & $2.75 \times 10^{10}$ & $1.62 \times 10^{8}$ & $2.42 \times 10^{7}$ & 0.6161 & 1.0161 & 0.1516 \\
\hline 0.4 & 0.157 & $3.29 \times 10^{10}$ & $1.78 \times 10^{8}$ & $2.58 \times 10^{7}$ & 0.7377 & 1.1177 & 0.1616 \\
\hline 0.7 & 0.088 & $3.97 \times 10^{10}$ & $1.72 \times 10^{8}$ & $2.53 \times 10^{7}$ & 0.8890 & 1.0786 & 0.1589 \\
\hline 1.0 & 0.034 & $4.40 \times 10^{10}$ & $1.65 \times 10^{8}$ & $2.23 \times 10^{7}$ & 0.9860 & 1.0349 & 0.1397 \\
\hline
\end{tabular}

a

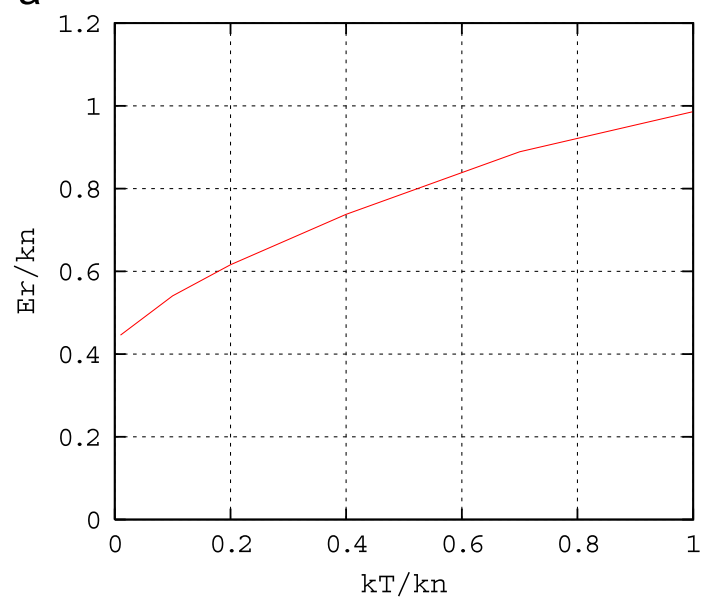

b

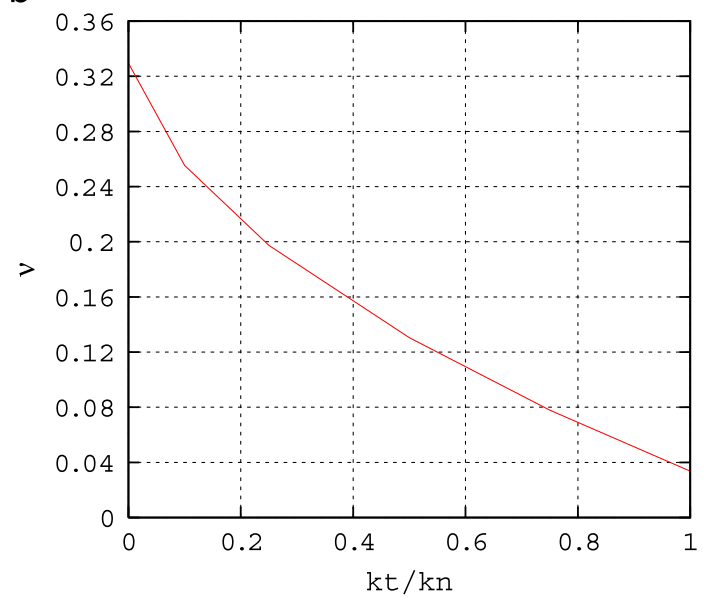

Fig. 13. ( $\mathrm{a}$ and $\mathrm{b}$ ) Elastic dimensionless parameters as functions of $k_{t} / k_{n}$ for the $3 \mathrm{D}$ model. 
a

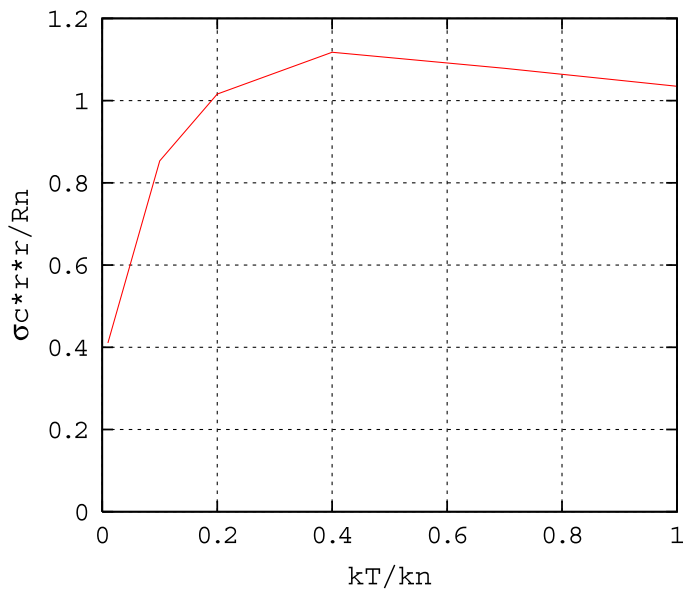

b

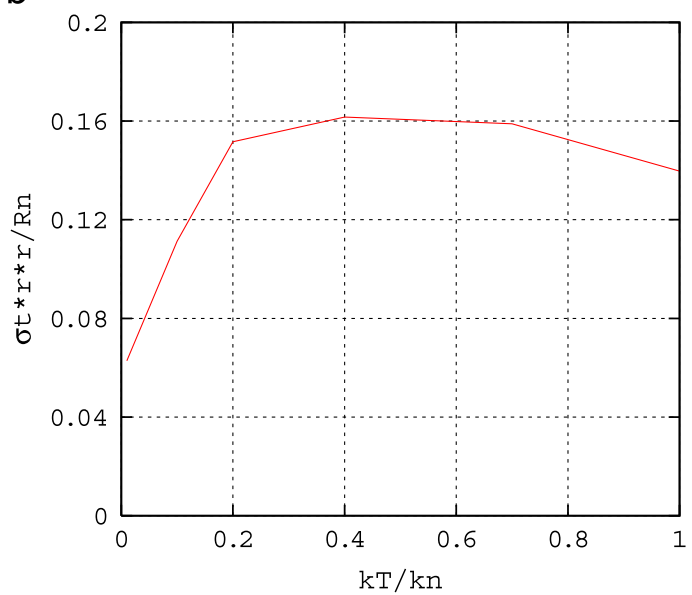

Fig. 14. Dimensionless compressive strength parameters as a function of $k_{t} / k_{\pi}$ : (a) for compression, (b) for tension for the $3 D$ model.

the simulations of the UCS test are plotted in Figs. 13 and 14a. The relationship (43) obtained from the numerical simulations of the Brazilian test is given in Fig. 14b.

5. Experimental studies of rock cutting with a single roadheader pick
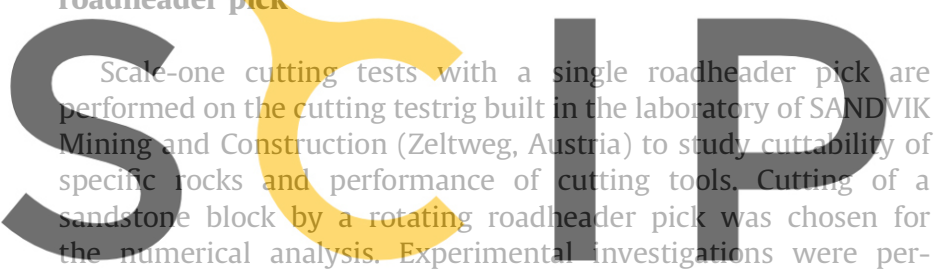

formed for the sandstone from Imberg (Germany). Its mineralogi-

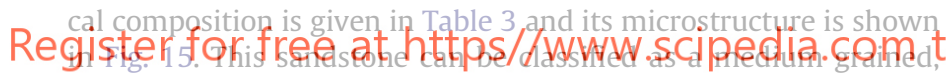

compact, homogenous and slightly metamorphous sandstone.

Mechanical properties of the rock have been determined experimentally and are the following: Young's modulus $E=$ 18,690 MPa, compressive strength $\sigma_{c}=127 \mathrm{MPa}$ and tensile strength $\sigma_{t}=12 \mathrm{MPa}$. Mechanical tests employed in the present work were limited to the UCS and Brazilian tests, which are the basic tests performed to characterize rocks in engineering practice. These tests are also used in the basic estimation of rock cuttability in the Sandvik laboratory. The performed tests have not provided with the information about the Poisson's coefficient of the rock. Numerical studies show that the Poisson's ratio is an important parameter in the cutting process [33]. Based on the literature we have assumed the value of around 0.25 for the Poisson coefficient of the investigated sandstone, although we must remember that this value is taken with quite high uncertainty.

The cutting process was performed with the velocity of $1.4 \mathrm{~m} / \mathrm{s}$ and the depth of cutting set at $10 \mathrm{~mm}$. The spacing between subsequent cuts was $20 \mathrm{~mm}$. During the tests three components of the cutting force, the cutting (tangential), normal and side components were registered. The cutting force components, obtained during the test selected for validation of the numerical model, are plotted as a function of the cutting distance in Fig. 16. Oscillations typical for cutting of brittle rocks can be observed. The average values of the three components of cutting forces and respective standard deviations are given in Table 4.

Force oscillations are correlated with chip formation process. The spacing between force peaks in Fig. 16 corresponds to chip

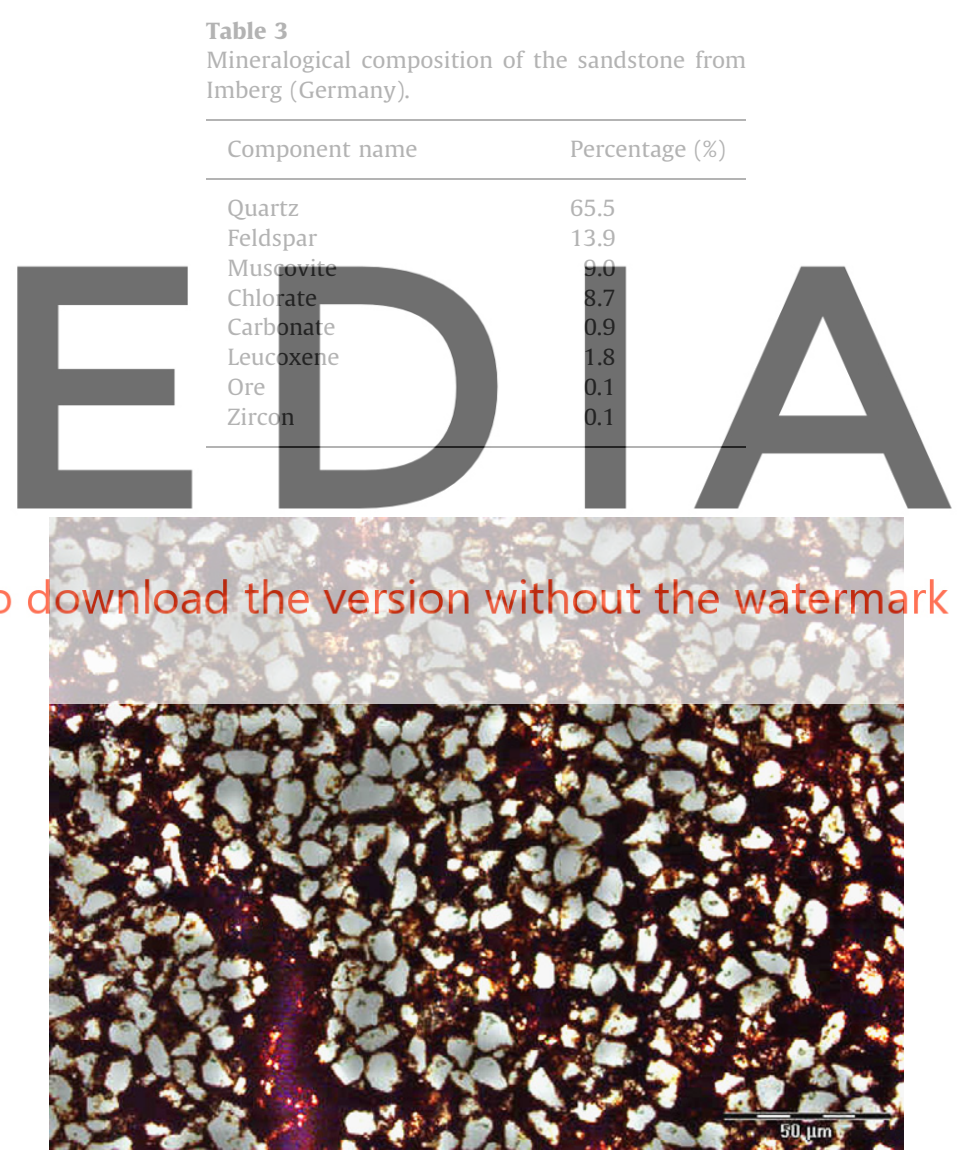

Fig. 15. Microstructure of Imberg sandstone.

sizes. The relationship of force oscillation and chip sizes can be analysed using frequency spectra of cutting forces. Frequency spectra of any time function can be generated via the fast Fourier transformation [6]. Analysis of cutting force oscillations in the time domain allows us to estimate intervals between main peaks, which correspond to major chip formation. Using noisy force time signals it is not possible to analyse effectively oscillations in higher frequencies, which are correlated with splitting of smaller chips. This can be done using representation of cutting forces in the frequency domain. Knowledge of frequency components of 


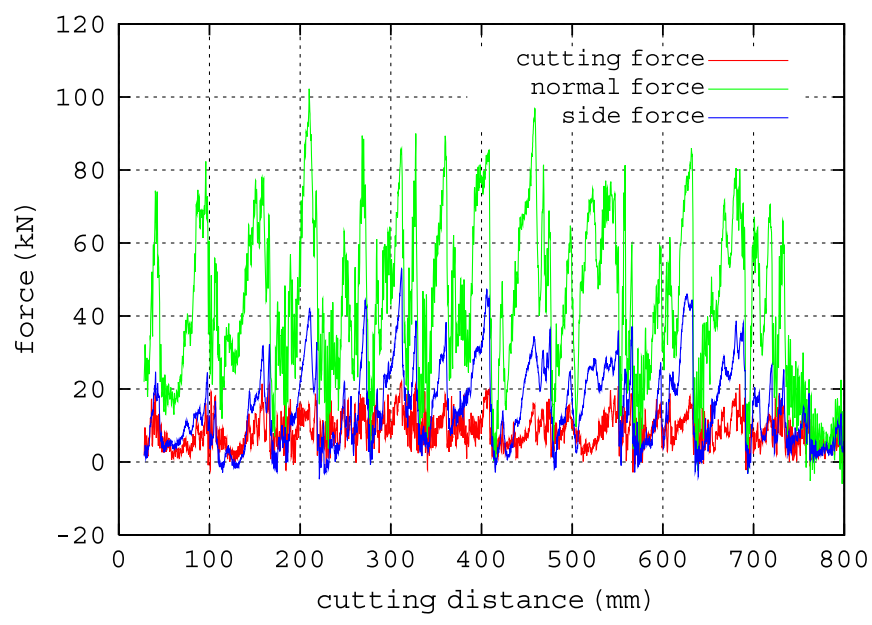

Fig. 16. Experimental cutting forces vs. cutting distance (laboratory of Sandvik Mining and Construction GmbH, Zeltweg, Austria). smallest size of chips can be calculated as

$l_{\text {chip }}^{\min }=\frac{v_{\text {cut }}}{f_{\mathrm{t}}}=\frac{1400}{217} \mathrm{~mm} \approx 6.5 \mathrm{~mm}$.

Oscillations of cutting forces can arise either from chip formation process or from vibrations of the testing equipment. The force amplitude peak in the range of higher frequencies $(700-750 \mathrm{~Hz})$ in the plot in Fig. 17 is probably due to vibrations of the cutting system, rather than arising from the chip formation process. The tool holder in the test rig is characterized with high stiffness so its high natural frequency corresponding to the frequency peak around $700 \mathrm{~Hz}$ is understandable.

Our conclusions from the frequency spectrum analysis are confirmed by the observations of the chips produced during the cutting test. Fig. 18 shows the chips grouped according to their size. The chip maximum dimension was used as a parameter characterizing chip size. Distribution of chip sizes is presented in the form of the histogram in Fig. 19. We can see that the range of the chip sizes

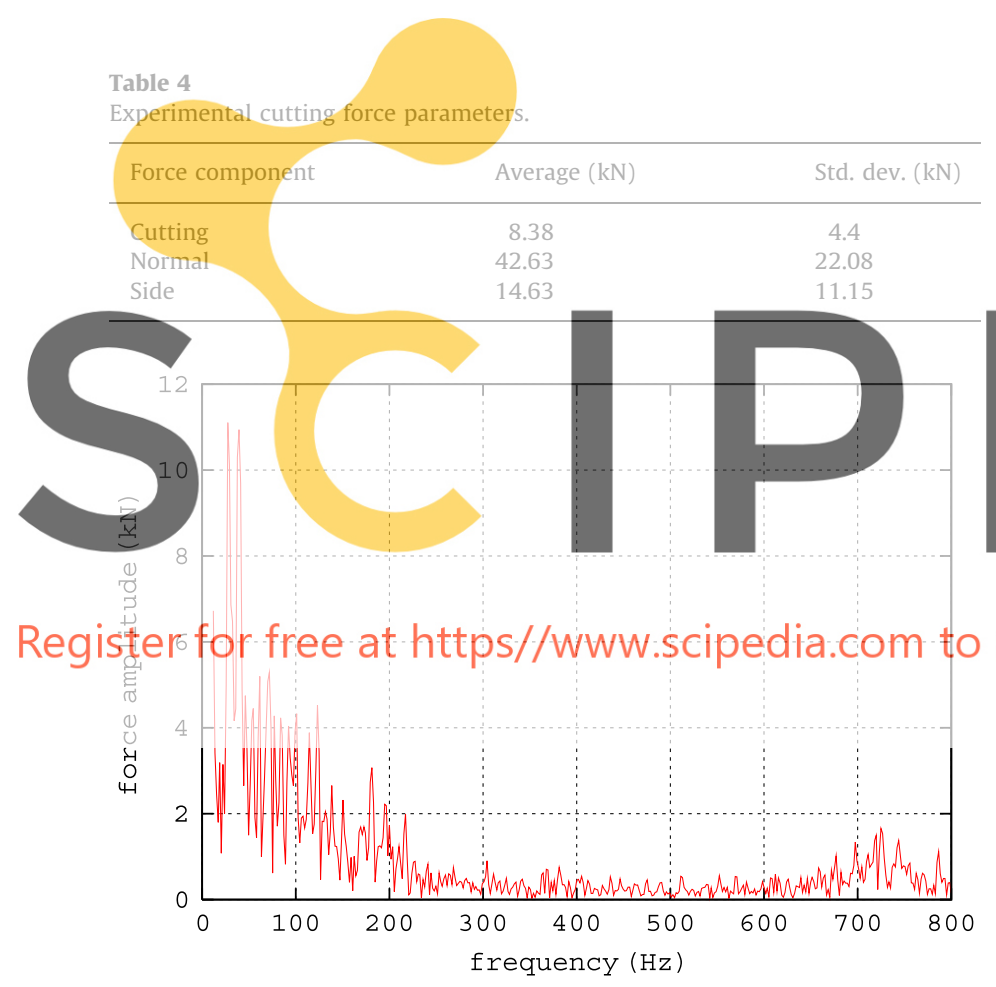

Fig. 17. Frequency spectrum of the experimental normal cutting force.

cutting force signals will enable us to estimate corresponding chip sizes, which is illustrated below.

Frequency spectrum of the normal force is presented in Fig. 17 as the plot of the force amplitude vs. frequency. It can be supposed that a prominent peak at frequency $f_{\mathrm{p}}=27 \mathrm{~Hz}$ corresponds to major chip formation. The major chip size $l_{\text {chip }}^{\max }$ in the cutting direction would be then

$l_{\text {chip }}^{\max }=\frac{v_{\text {cut }}}{f_{\mathrm{p}}}=\frac{1400}{27} \mathrm{~mm} \approx 52 \mathrm{~mm}$.

On the right side from the peak a range of frequencies with increased amplitudes can be observed, with the threshold frequency being approximately $217 \mathrm{~Hz}$. The range of frequencies $27-217 \mathrm{~Hz}$ corresponds to the chip formation process. The

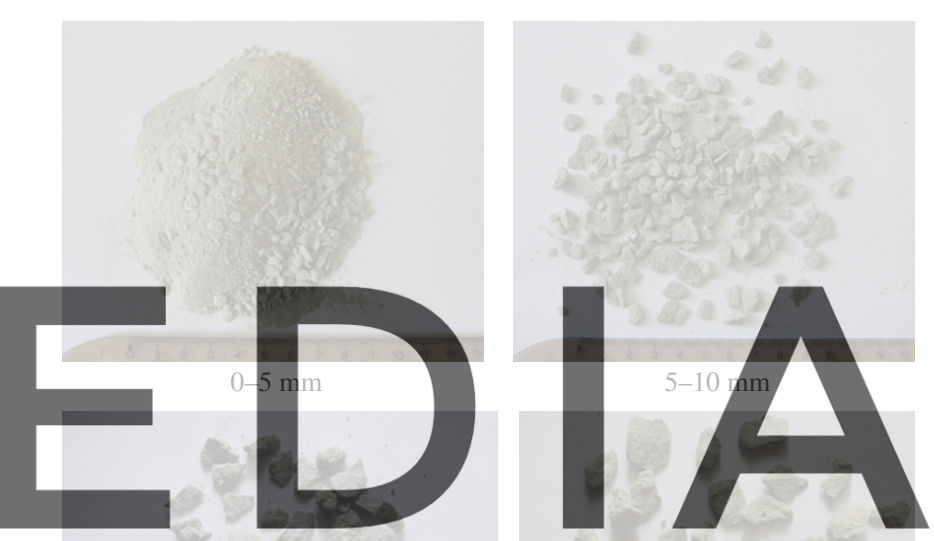

download the version without the watermark

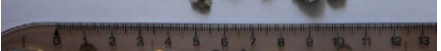

$10-15 \mathrm{~mm}$

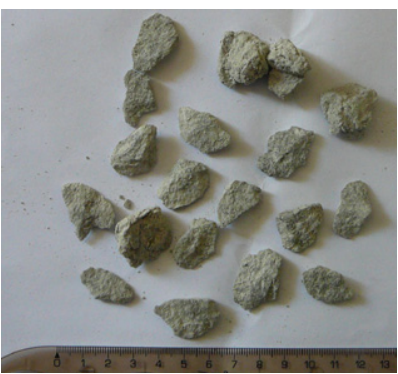

$20-25 \mathrm{~mm}$

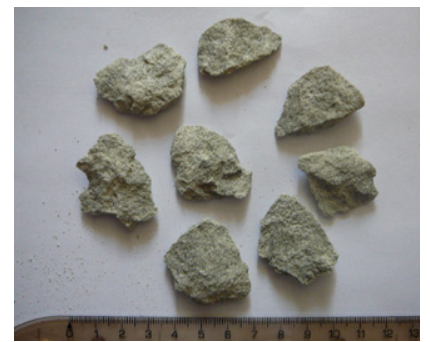

$30-35 \mathrm{~mm}$

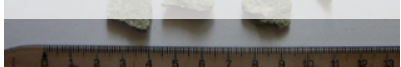

$15-20 \mathrm{~mm}$

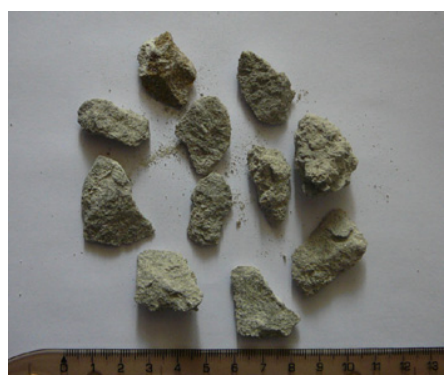

25-30 $\mathrm{mm}$

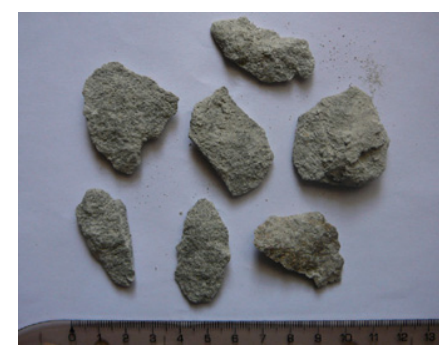

$35-40 \mathrm{~mm}$
Fig. 18. Rock chips sizes. 


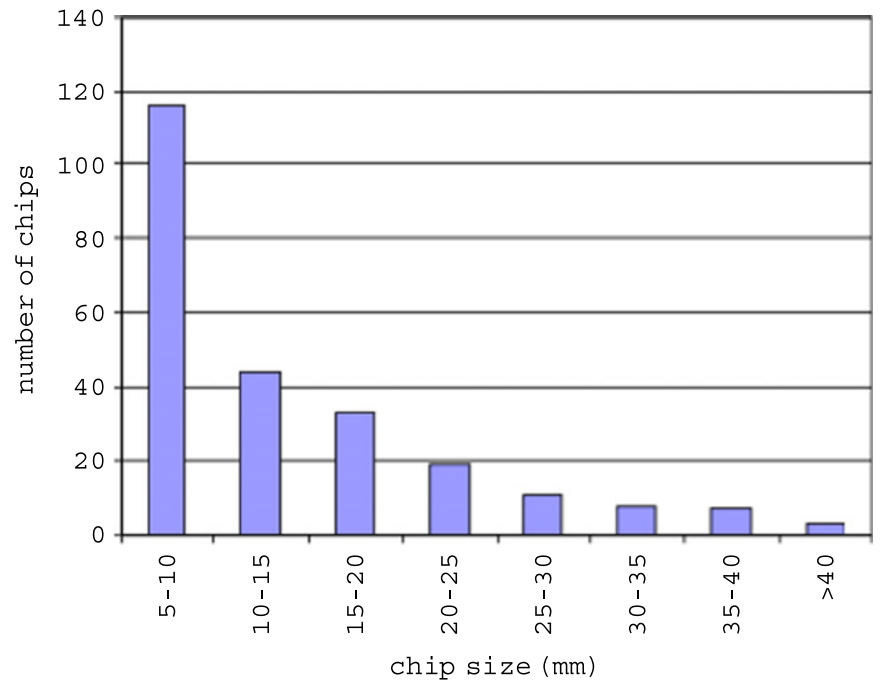

Fig. 19. Laboratory rock cutting tests-chips size histogram. a

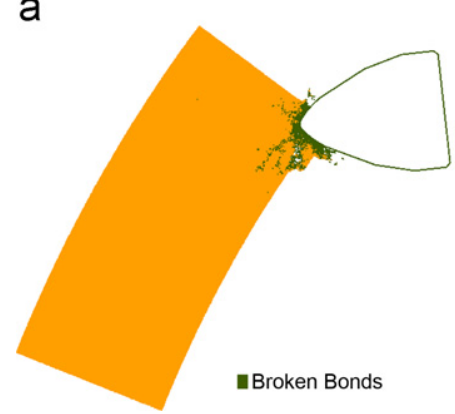

b

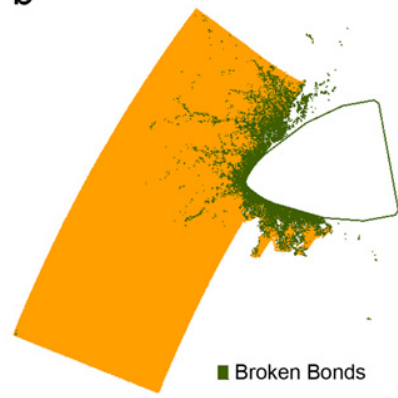

Fig. 20. ( $a$ and b) 2D numerical simulation of rock cutting_failure mode during rock cutting.

are in perfect accordance with the sizes predicted by the analysis of the frequency spectrum.

\section{2D simulation of the rock cutting test}

The discrete element model has been applied to simulation of the rock cutting test described assuming 2D and 3D geometry. The 2D simulation is shown in Fig. 20. The rock specimen is discretized using 97,960 cylindrical elements of radii in the range $r=0.0796-0.345 \mathrm{~mm}$ and with the average radius $\bar{r}=0.2 \mathrm{~mm}$. The tool has been discretized with 1090 straight line segments.

The discrete element model parameters have been determined using the dimensionless relationships (35)-(37) plotted in Figs. $13-14$. We have assumed the value of the ratio $k_{t} / k_{n}$ is 0.1 . This value corresponds to the Poisson's ratio of 0.224 (cf. Fig. 10b) which is approximately a likely value of the Poisson's ratio for the investigated sandstone. Qualitative analysis of the results of simulations of the UCS and Brazilian tests indicates that for the assumed value of the ratio $k_{t} / k_{n}$ a brittle behaviour of the rock is represented properly. For the given $k_{t} / k_{n}=0.1$ from the plot in Fig. 13a we have $E / k_{n}=0.98$, and this yields $k_{n}=1.869 \times$ $10^{10} / 0.98=1.94 \times 10^{10} \mathrm{~N} / \mathrm{m}$. The strength of the cohesive bonds in the normal direction $R_{n}$ can be calculated either from the plot in Fig. 14a or from the one in Fig. 14b. The former gives $R_{n}=$ $\sigma_{c} \cdot \bar{r} / 1.4=127 \times 10^{6} \cdot 0.2 \times 10^{-3} / 1.4=18.1 \times 10^{3} \mathrm{~N}$, whereas the latter gives $R_{n}=\sigma_{t} \cdot \bar{r} / 0.18=12 \times 10^{6} \cdot 0.2 \times 10^{-3} / 0.18=$ $13.4 \times 10^{3} \mathrm{~N}$. Since the rock failure in cutting is related to tensile stresses, the strength of the cohesive bonds calibrated according to the rock tensile strength $R_{n}=13.4 \times 10^{3} \mathrm{~N}$ has been taken. The bond strength in the tangential direction $R_{t}$ has been assumed as equal to $R_{n}$, similarly as in the calibration procedure presented in Section 4.1.1.

The set of microscopic parameters has been completed with the Coulomb friction coefficient $\mu=0.839$, the parameters of the rock-tool interaction and the coefficients of the global damping. For the rock-tool interaction the following set of parameters has been assumed: $k_{\mathrm{n}}=k_{\mathrm{s}}=5 \times 10^{10} \mathrm{~N} / \mathrm{m}, \mu=0.5$. The non-viscous damping has been assumed taking the damping factors $\alpha^{\mathrm{nvt}}=\alpha^{\mathrm{nvr}}=0.2$.

The rock failure mode obtained in the simulation (Fig. 20) is in accordance with the failure observed in the laboratory test. The cutting forces predicted in the 2D simulation have been plotted in

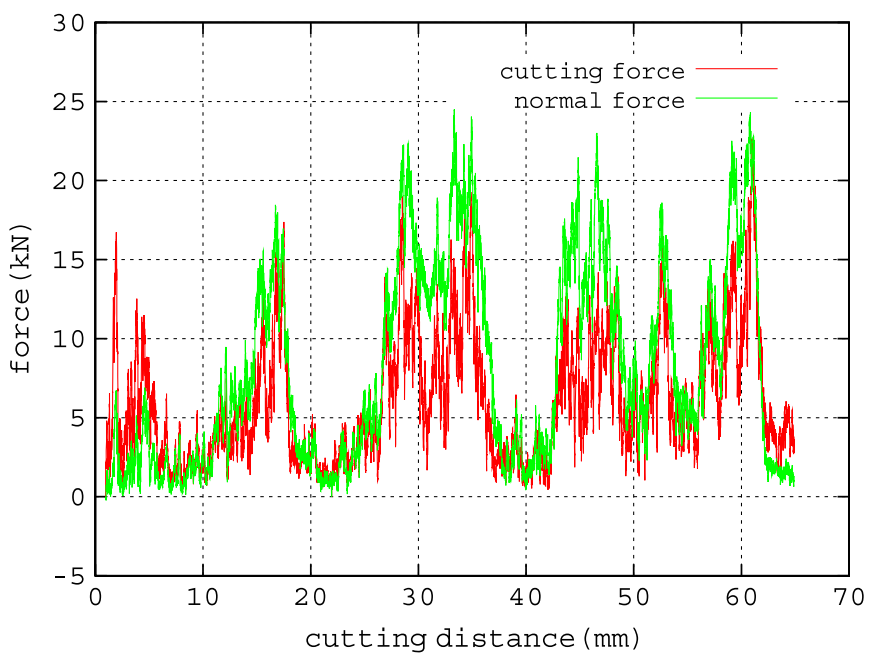

Fig. 21. 2D numerical simulation of rock cutting_cutting force variation.

Table 5

Cutting force parameters predicted in the 2D simulation.

\begin{tabular}{lll}
\hline Force component & Average $(\mathrm{kN})$ & Std. dev. $(\mathrm{kN})$ \\
\hline Cutting & 6.1 & 4.0 \\
Normal & 8.14 & 6.28 \\
\hline
\end{tabular}

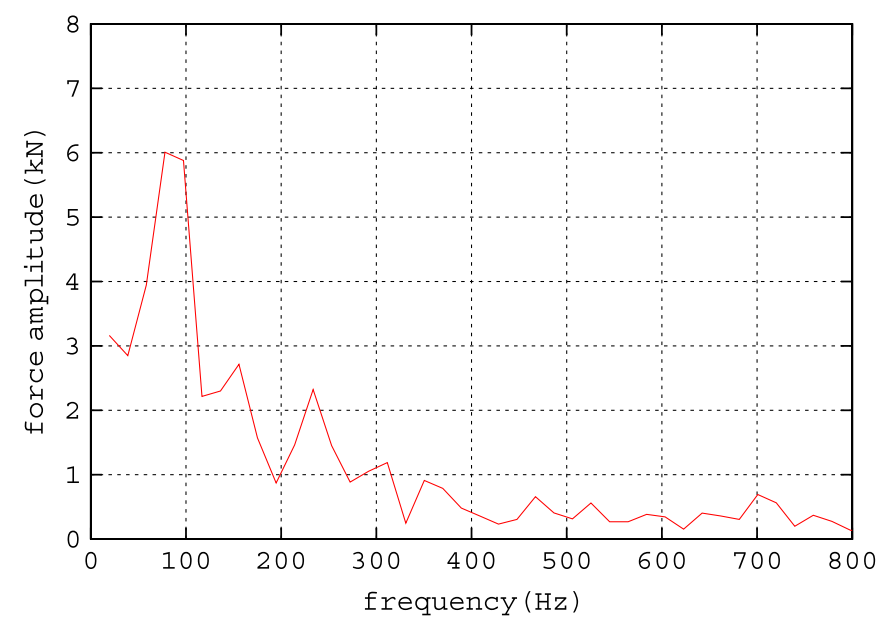

Fig. 22. 2D numerical simulation of rock cutting-frequency spectrum of the normal force. 
Fig. 21. The average values and standard deviation of the cutting force components are given in Table 5.

The cutting forces have been transformed into frequency domain using the Fourier transformation. The frequency spectrum of the normal component of the cutting force is plotted in Fig. 22. Similarly to the experimental spectrum a peak amplitude and the range with increased amplitudes are observed. The characteristic frequencies 78 and $233 \mathrm{~Hz}$ allow us to predict the chip size range $6-18 \mathrm{~mm}$.

\section{3D simulation of the rock cutting test}

All the three components of the cutting force can be calculated using a three-dimensional model of the rock cutting test. Results of the 3D simulation are shown in Fig. 23. The material sample has been discretized using 71,200 spherical particles with average radius of $1.02 \mathrm{~mm}$. The discrete element assembly has been generated using the high density sphere packing algorithm [17]. The tool was assumed as rigid and its surface was discretized with a fine mesh of triangular facets representing accurately a complex tool tip geometry.

The micromechanical parameters for the considered rock were found with help of dimensionless relationships given in Figs. 13a and 14a. Similarly like in the 2D model, the ratio between the contact stiffness in the tangential and normal direction $k_{t} / k_{n}$ has been assumed as equal to 0.1 . This value corresponds to the Poisson's ratio of 0.265 (cf. Fig. 14b) which is a likely value of the Poisson's ratio for the investigated sandstone. Brittle behaviour of the rock is represented properly in the model for this value of the ratio $k_{t} / k_{n}$. From the curve given in Fig. 13a the contact stiffness in the normal direction $k_{n}=1.869 \times 10^{10} \cdot 1.02 \times 10^{-3} / 0.52=$ $3.6 \times 10^{7} \mathrm{~N} / \mathrm{m}$ has been obtained, then we have the contact stiffness in the tangential direction $k_{\mathrm{t}}=3.6 \times 10^{6} \mathrm{~N} / \mathrm{m}$. The value of cohesive bond strengths in the normal $R_{n}$ can be calculated from the plots in Fig. 14a or b. The results obtained from these two plots are slightly different, $R_{n}=\sigma_{c} \cdot \bar{r}^{2} / 0.88=127 \cdot 10^{6} \times$ $\left(1.02 \times 10^{-3}\right)^{2} / 0.88=150 \mathrm{~N}$ from the plot in Fig. $14 \mathrm{a}$ vs. $R_{n}=\sigma_{t}$. $\bar{r}^{2} / 0.103=12 \times 10^{6} \cdot\left(1.02 \times 10^{-3}\right)^{2} / 0.103=121 \mathrm{~N}$ from Fig. $14 \mathrm{~b}$. Since the failure in cutting of sandstone is of brittle character and splitting of chips is mainly due to tensile stresses, the value $R_{n}=121 \mathrm{~N}$ according to the indirect tensile test simulation results has been adopted. Similar value for the shear bond strength has been taken, $R_{t}=121 \mathrm{~N}$.

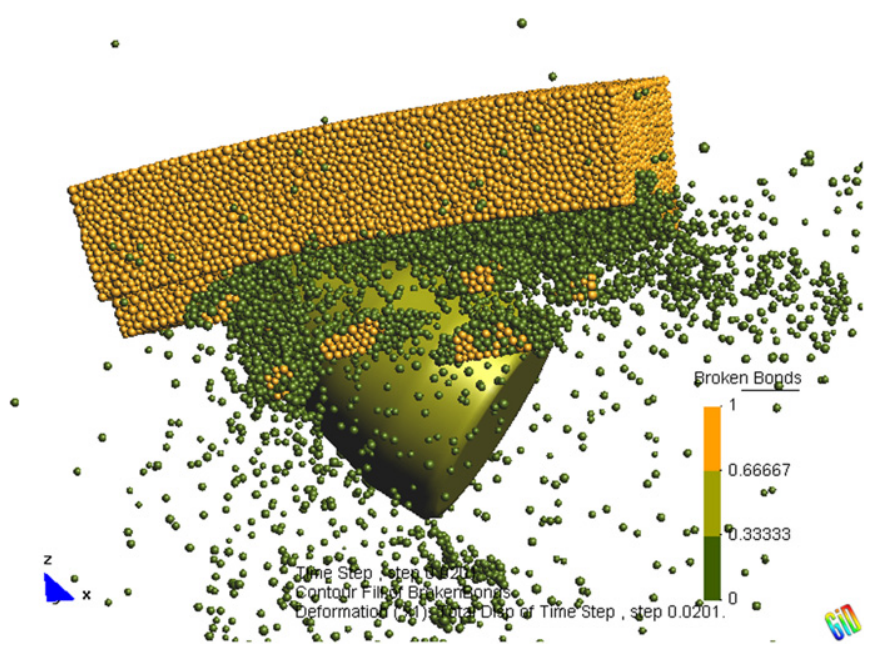

Fig. 23. Numerical simulation of the laboratory rock cutting test.
The set of microscopic parameters has been completed with the Coulomb friction coefficient $\mu=0.839$, the parameters of the rock-tool interaction: $k_{\mathrm{n}}=k_{\mathrm{t}}=3.6 \times 10^{6} \mathrm{~N} / \mathrm{m}, \mu=0.5$, and the non-viscous damping factors $\alpha^{\mathrm{nvt}}=\alpha^{\mathrm{nvr}}=0.2$.

The results of numerical simulation (Fig. 23) show that splitting of chips typical for brittle rock cutting has been reproduced in numerical simulation. The three components of cutting forces obtained in simulation are plotted in Fig. 24.

The frequency spectrum of the normal component of the cutting force is plotted in Fig. 25. The peak amplitude corresponding to the major chip formation is at frequency $49 \mathrm{~Hz}$, which gives the major chip size $28 \mathrm{~mm}$. The threshold frequency for the chip formation process is approximately $230 \mathrm{~Hz}$, which yields the size of small chips $6 \mathrm{~mm}$ (Table 6).

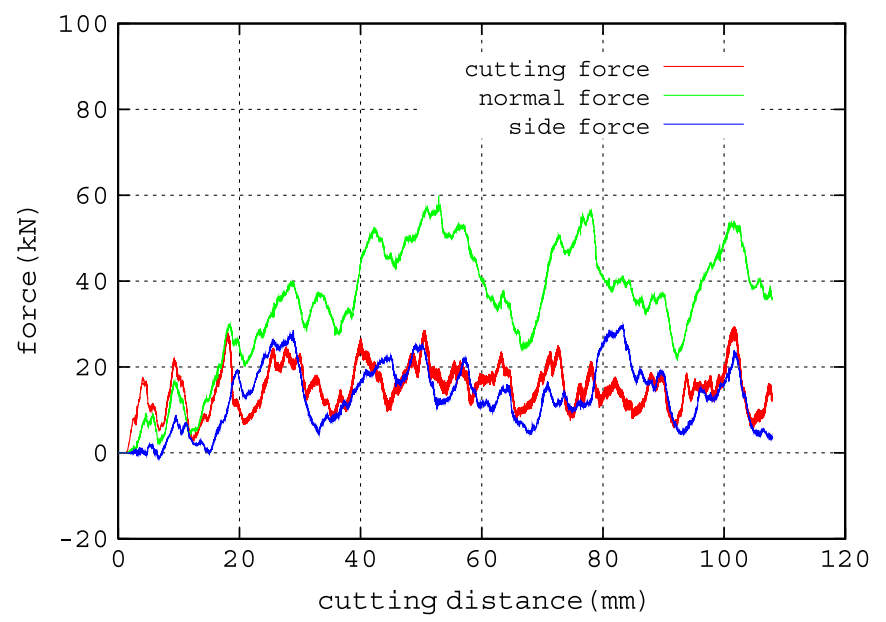

Fig. 24. Rock cutting forces-3D numerical results.

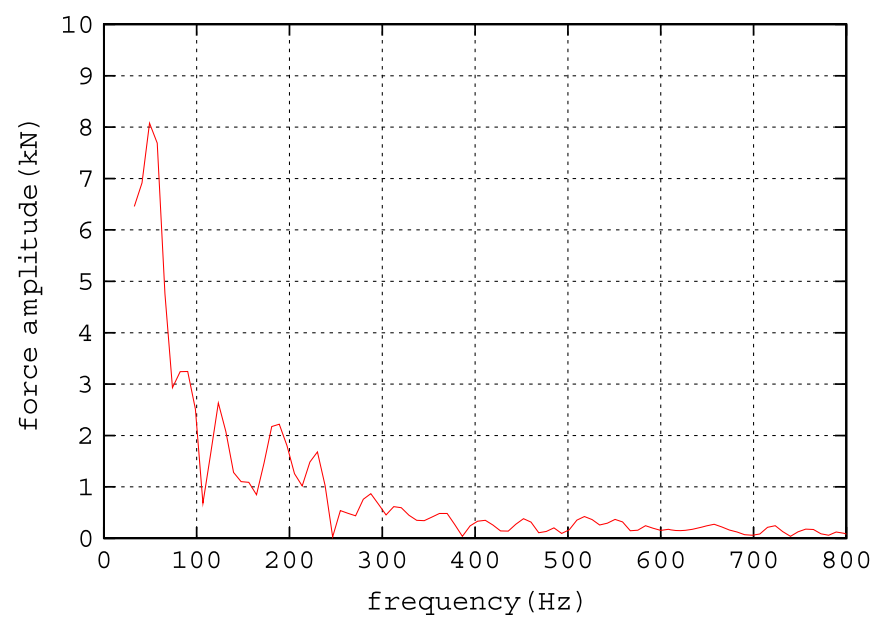

Fig. 25. 3D numerical simulation of rock cutting-frequency spectrum of the normal force.

Table 6

Cutting force parameters predicted in the 3D simulation.

\begin{tabular}{llc}
\hline Force component & Average $(\mathrm{kN})$ & Std. dev. $(\mathrm{kN})$ \\
\hline Cutting & 14.8 & 5.4 \\
Normal & 35.00 & 14.11 \\
Side & 12.92 & 7.49 \\
\hline
\end{tabular}




\section{Comparison of numerical and experimental results}

Fig. 26 shows comparison of the experimental and the numerically predicted cutting forces given by their average values and standard deviations. Despite the differences observed in the average values and in the values of the standard deviations, the numerical analysis both in 2D and 3D gives quite good prediction of the cutting force. The 2D model has no capability to predict the side component and the prediction of the normal component is not correct. This is caused mainly by the lack of full geometrical information in the 2D model. Furthermore, the 2D simulations are based on the assumption of plain strain conditions, what may be appropriate for prism shaped radial tools, but it is not adequate to model the cutting with point attack tools. Consequently, a reasonable prediction of all three components of the cutting forces can be obtained using the $3 \mathrm{D}$ model.

Plots of the force spectra (Fig. 27) indicate that the simulation results - especially those of the $3 \mathrm{D}$ simulation - matching quite well the experimental results. In the numerical spectra, similarly as in the experimental results, the peak amplitude is predicted, and a certain range with increased amplitudes can be detected allowing us to predict the chip sizes. The range of chip sizes predicted by numerical simulation overlaps the range found in

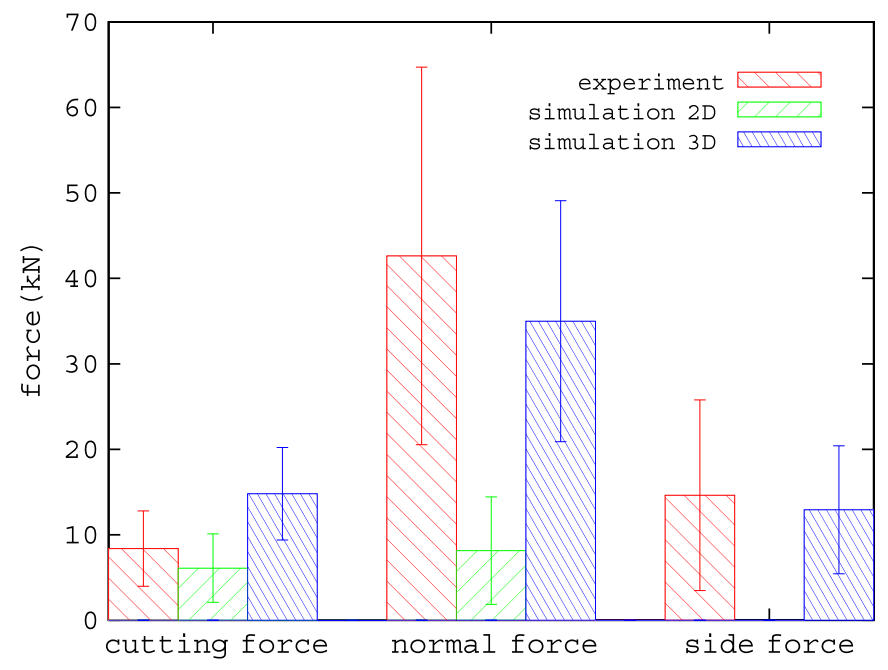

Fig. 26. Comparison of mean forces and standard deviations obtained in experiment and predicted in 2D and 3D simulations.

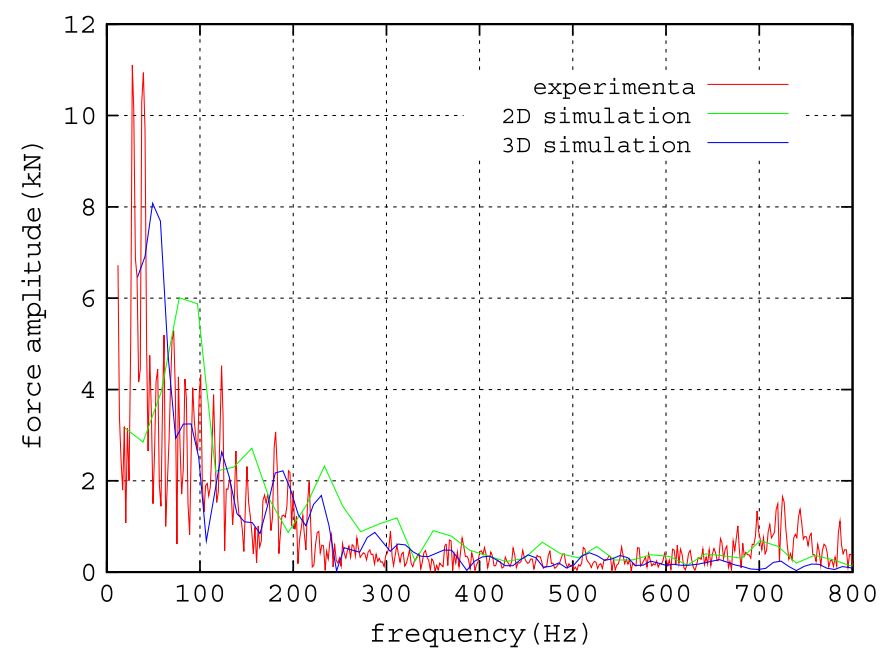

Fig. 27. Comparison of force frequency spectrums obtained in experiment and predicted in 2D and 3D simulations. the laboratory tests. While the size of smaller chips is predicted with a high accuracy by both the 2D and 3D simulation, the major chip size is predicted with a larger error-a better coincidence with the experimental results is obtained for the $3 \mathrm{D}$ simulation.

\section{Concluding remarks}

The numerical simulation can provide valuable information about the cutting phenomenon. The discrete element model of rock cutting is capable to represent correctly complexity of a rock cutting process. Quite a good qualitative and quantitative agreement of numerical results with experimental measurements has been found in the validation of the model developed in the present work. The discrete element model developed can be employed in the design of rock cutting tools and processes.

The discrete element model of rock cutting requires further validation. More rigorous calibration of the model would require a more comprehensive experimental testing procedure including the triaxial compression, direct shear and fracture mechanics tests relevant to rock failure in rock cutting. It can be expected that the use of the results of these tests for model calibration could allow us to tune model parameters better and subsequently improve qualitative results in the analysis of rock cutting.

\section{Acknowledgement}

The authors acknowledge partial funding by the EU project TUNCONSTRUCT (contract no. IP 011817-2).

\section{Appendix A. Numerical algorithm}

The flowchart of the main routine of the discrete element method program DEMPack performing simulation of a rock cutting process is given in Fig. 28.

\section{Appendix B. Input data}

The following data are necessary to define completely a numerical model of rock cutting presented in this paper:

Geometry definition of a rock specimen: Discretized geometry of a rock specimen is given by the set of spherical particles defined by their radii $r_{i}$ and their centroids $\left(X_{i}, Y_{i}, Z_{i}\right), i=1, \ldots, N_{p}$, where $N_{p}$ is the number of particles.

Geometry definition of a rock cutting tool: The tool geometry is defined by a triangularized tool surface. The triangular mesh is given by the set of nodes $\left(X_{i}, Y_{i}, Z_{i}\right), i=1, \ldots, N_{t}$, where $N_{t}$ is the number of nodes used in the tool discretization, and the node connectivities.

Kinematic conditions: Kinematic conditions can be specified by fixing any degrees of freedom of arbitrary nodes or by prescribing any component of translational or rotational nodal velocity using a given function of time. In particular, the tool trajectory is defined by prescribing the tool velocity.

Load: Gravitational load and arbitrary nodal forces can be introduced. Loading can be either constant or scaled by an arbitrary time function.

Initial conditions: Non-zero initial velocities and displacements can be specified optionally. If not specified, zero initial velocities and displacements are assumed.

Material properties: The complete set of parameters defining material properties in the discrete element model is the following:

$k_{\mathrm{n}} \quad$ contact stiffness in the normal direction,

$k_{\mathrm{t}} \quad$ contact stiffness in the tangential direction, 


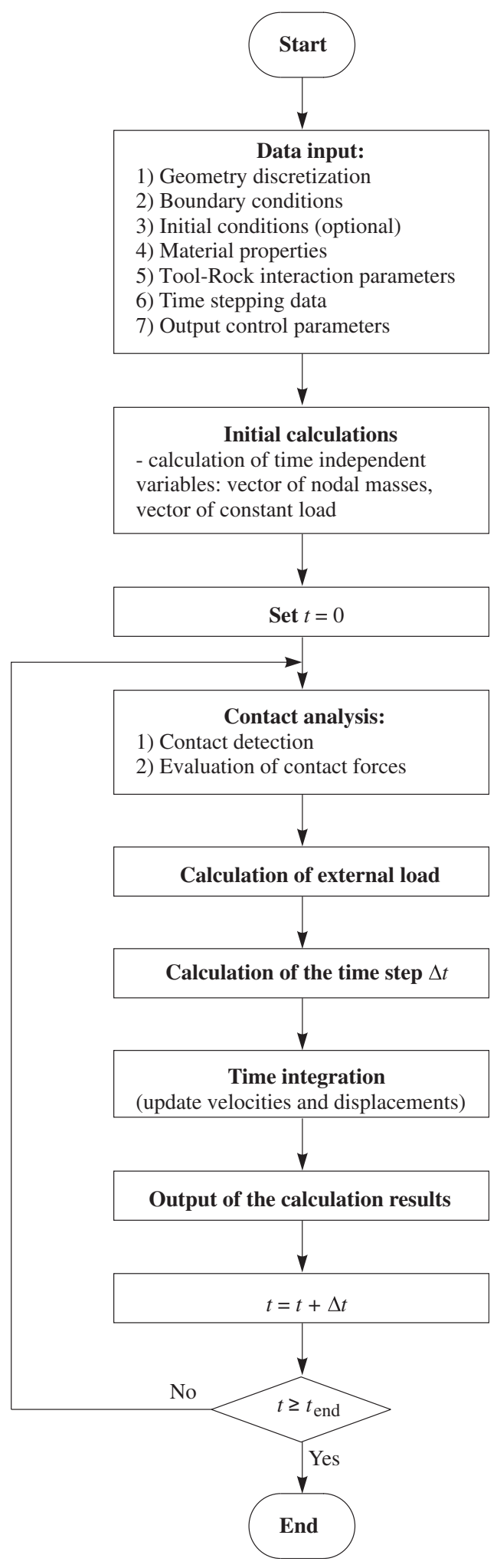

Fig. 28. Flowchart of simulation of a rock cutting process.

$R_{\mathrm{n}} \quad$ interface strength in the normal direction,

$R_{\mathrm{t}} \quad$ interface strength in the tangential direction,

$\mu \quad$ Coulomb friction coefficient,

$\alpha^{t} \quad$ damping coefficient for translational motion,

$\alpha^{r} \quad$ damping coefficient for rotational motion.
Cohesive bonds are imposed for the particles being in contact at the initial configuration. The contact bonding is also established for the particles being very close to one another. A certain small tolerance, $g_{\text {tol }}$, is used in verification of initial contact condition. In the present work this condition has been assumed proportional to the average particle radius $r, g_{\text {tol }}=0.01 r$.

Tool-Rock interaction parameters: The frictional model of tool-rock interaction is defined using the following parameters:

$k_{\mathrm{n}} \quad$ contact stiffness in the normal direction,

$k_{\mathrm{t}} \quad$ contact stiffness in the tangential direction,

$\mu \quad$ Coulomb friction coefficient.

Time stepping data: The following parameters are used to control process time and time integration:

$t_{\text {end }} \quad$ end time of the analysis,

$\alpha \quad$ safety factor in the estimation of the stable time step.

\section{Appendix C. Result output}

Complete solution: A complete solution is saved at specified intervals $t_{\text {outp. }}$.

- The following results are saved:

- nodal displacements,

- nodal velocities,

- nodal accelerations,

- particle interaction forces,

- cohesive bond state flag: bond active or broken,

- averaged density,

- averaged stresses.

Selected results: Selected results are output at higher frequency, at specified intervals $t_{\text {hist }}$. The following selected results are saved for plotting time histories:

- interface contact forces,

- selected nodal accelerations,

- selected nodal velocities,

- selected nodal displacements.

\section{References}

[1] Argyris J. An excursion into large rotations. Computer Methods in Applied Mechanics and Engineering 1982;32:85-155.

[2] Balci C, Bilgin N. Correlative study of linear small and full-scale rock cutting tests to select mechanized excavation machines. International Journal of Rock Mechanics and Mining Sciences 2007;44(3):468-76.

[3] Belheine N, Plassiard JP, Donzé FV, Darve F, Seridi A. Numerical simulation of drained triaxial test using $3 \mathrm{~d}$ discrete element modeling. Computers and Geotechnics 2009;36:320-31.

[4] Belytschko T, Smolinski P, Liu WK. Stability of multi-time step partitioned integrators for the first order finite element systems. Computer Methods in Applied Mechanics and Engineering 1985;49:281-97.

[5] Bilgin N, Demircin MA, Copur H, Balci C, Tuncdemir H, Akcin N. Dominant rock properties affecting the performance of conical picks and the comparison of some experimental and theoretical results. International Journal of Rock Mechanics and Mining Sciences 2006;43(1):139-56.

[6] Duhamel P, Vetterli M. Fast Fourier transforms: a tutorial review and a state of the art. Signal Processing 1990;19:259-99.

[7] Evans I. The force required for pointed attack picks. International Journal of Mining Engineering 1965;2:63-71.

[8] Fakhimi A, Villegas T. Application of dimensional analysis in calibration of a discrete element model for rock deformation and fracture. Rock Mechanics and Rock Engineering 2007;40(2):193-211.

[9] Gong QM, Zhao J, Hefny AM. Numerical simulation of rock fragmentation process induced by two tbm cutters and cutter spacing optimization. Tunnelling and Underground Space Technology 2006;21:263-70. 
[10] Guo H, Aziz NI, Schmidt LC. Rock cutting study using linear elastic fracture mechanics. Engineering Fracture Mechanics 1992;41:771-8.

[11] Huang $H$. Discrete element modeling of tool-rock interaction. PhD thesis. University of Minnesota; 1999.

[12] Jonak J, Podgórski J. Mathematical model and results of rock cutting modelling. Journal of Mining Science 2001;37:615-8.

[13] Khair AW. The effect of bit geometry on rock cutting efficiency. Applied Occupational and Environmental Hygiene 1996;11(7):695-700.

[14] Korinets AR, Alehossein H, Chen L, Lim W, Baker G. DIANA modeling of a rolling disc cutter and rock indentation. In: M. Aubertinin, F. Hassani, M. Mitri (Eds.), Rock Mechanics, Tools and Techniques, Rotterdam, Balkema; 1996. p. 647-54.

[15] Kou SQ, Lindqvist PA, Tang CA, Xu XH. Numerical simulation of the cutting of inhomogeneous rocks. International Journal of Rock Mechanics and Mining Sciences 1999;36:711-7.

[16] Kruyt NP, Rothenburg L. Kinematic and static assumptions for homogenization in micromechanics of granular materials. Mechanics of Materials 2004;36:1157-73.

[17] Labra C, Oñate E. High density sphere packing for discrete element method simulations. Communications in Numerical Methods in Engineering 2009;25(7):837-49.

[18] Langhaar HL. Dimensional analysis and theory of models. Wiley; 1951.

[19] Lei S, Kaitkay P, Shen X. Simulation of rock cutting using distinct element method-PFC2D. In: Shimizu H, Cundall, editors, Numerical modeling in micromechanics via particle methods-2004. Taylor \& Francis; 2004. p. 63-71.

[20] Liu SY, Du CL, Cui XX. Research on the cutting force of a pick. Mining Science and Technology 2009;19:514-7.

[21] Lunow C, Konietzky H. Two dimensional simulation of the pressing and the cutting rock destruction. In: Proceedings of EURO:TUN 2009 II international conference on computational methods in tunnelling. Bochum, Germany; 2009.

[22] Nishimatsu Y. The mechanics of rock cutting. International Journal of Rock Mechanics and Mining Sciences 1972;9:261-70.
[23] Oñate E, Rojek J. Combination of discrete element and finite element methods for dynamic analysis of geomechanics problems. Computer Methods in Applied Mechanics and Engineering 2004;193:3087-128.

[24] Rojek J, Oñate E, Zarate F, Miquel J. Modelling of rock, soil and granular materials using spherical elements. In: Second european conference on computational mechanics ECCM-2001. Cracow; 26-29 June 2001.

[25] Roxborough FF. Cutting rocks with picks. Mining Engineer 1973;132:445-54

[26] Shenghua Y. Simulation of rock cutting by the finite element method. In: International ANSYS conference proceedings; 2004. p. 61-71.

[27] Stavropoulou M. Modeling of small-diameter rotary drilling tests on marbles. International Journal of Rock Mechanics and Mining Sciences 2006;43: 1034-51.

[28] Su O, Ali Akcin N. Numerical simulation of rock cutting using the discrete element method. International Journal of Rock Mechanics and Mining Sciences 2011;48:434-42.

[29] Su O, Akcin NA, te Kamp, L. Modeling of cutting forces acting on a conical pick. In: Proceedings of EURO:TUN 2009 II international conference on computational methods in tunnelling. Bochum, Germany; 2009.

[30] Whittaker BN, Szwilski AB. Rock cutting by impact action. International Journal of Rock Mechanics and Mineral Science Geomechanics Abstracts 1973;9:659-71.

[31] Xia H, Wang K, Zhai Y, Cai J. Experimental research of PDC cutter shapes on breaking rock efficiency under various confining pressures. Journal of Jianghan Petroleum Institute 1997;19(4):48-50.

[32] Yang B, Jiao Y, Lei S. A study on the effects of microparameters on macroproperties for specimens created by bonded particles. Engineering with Computer 2006;23(6):607-31.

[33] Yu B, Khair AW. Numerical modeling of rock ridge breakage in rotary cutting. In: ARMA general meeting. Vancouver, British Columbia, Canada; 2007.

[34] Yua Y, Yinb J, Zhong Z. Shape effects in the Brazilian tensile strength test and a 3D FEM correction. International Journal of Rock Mechanics and Mining Sciences 2006;43:623-7. 